\title{
Using CFD as a Design Tool on New Innovative Airliner Configurations
}

\author{
Bryan H. Blessing ${ }^{1}$, John Pham ${ }^{1}$, and David D. Marshall ${ }^{2}$ \\ California Polytechnic State University San Luis Obispo, San Luis Obispo, CA, 93407-0352
}

This paper demonstrates the use of CFD thus far as a design tool in evaluating aerodynamic performance for a NASA Research Announcement (NRA) project. The NRA project is carried out in two phases over the coarse of three years. Phase I utilizes CFD to evaluate and down select between two proposed future generation CESTOL airliner concepts; the Hybrid Wing-Body and the Blended Wing-Body. Both configurations are simulated at takeoff and cruise conditions to provide the means to making a final decision on which concept to continue forward with in Phase II. This second phase will take the proposed airliner concept and develop a wind tunnel model that will be used to generate validation data for CFD codes. The CFD analysis carried out in Phase I concluded that the preliminary Hybrid Wing-Body concept provides better CESTOL performance over the Blended Wing-Body concept. Through the use of CFD, this design will be further refined and analyzed to yield a possible future airliner configuration. The focus of this paper will explain the methodologies and techniques used in the meshing and numerical simulation process that generated the data needed to make a final decision for Phase I.

$\begin{array}{ll}C A D & =\text { computer aided drafting } \\ C C W & =\text { circulation control wing } \\ U S B & =\text { upper surface blowing }\end{array}$

\section{Nomenclature}

\section{Introduction}

$\mathrm{T}^{\mathrm{s}}$ HIS paper's intention is to show the progress of ongoing efforts to using computational fluid dynamics (CFD) as a design tool for a NASA Research Announcement (NRA) project. One of the primary purposes of the NASA contract is to develop and validate predictive capabilities for the design and performance of a 100 passenger $\mathrm{N}+2$ generation Cruise Efficient, Short Take-Off and Landing (CESTOL) subsonic aircraft configuration. This contract will be carried out in two phases over the course of three years. The first year (Phase I) will be to select and further refine one CESTOL airliner concept. The project started out studying four different airliner configurations designed by the research team. A down selection process was performed to reduce the number of configurations studied down to two to become the focus of computational efforts.

The first configuration shown in Figure 1 is what is being called the "hybrid blended-wing-body (HWB)." This particular configuration has been investigated in great depth, much more so, than the other three proposed concepts, and the design has gone through a design process that required numerous iterations just to meet the detailed requirements of the aerodynamic analysis. This design has two engines installed over the wing with the idea that the wing will provide shielding of community noise from the engines. This design requires dedicated gas generators buried in each wing root to supply air to the wing slots.

\footnotetext{
${ }^{1}$ Graduate Student, Aerospace Engineering Dept. Student Member.

${ }^{2}$ Associate Professor, Aerospace Engineering Dept. Senior Member.
} 


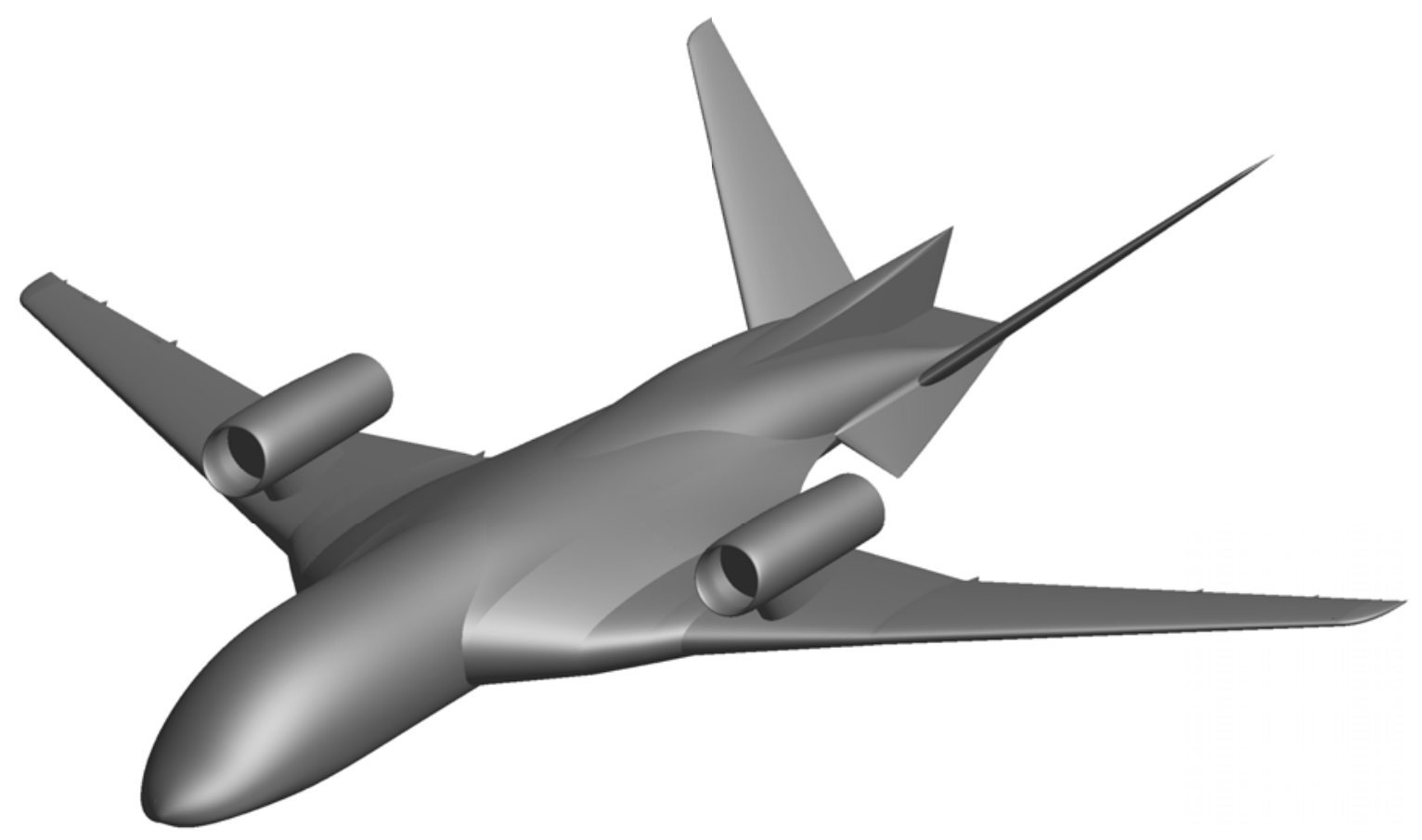

Figure 1: Hybrid Wing-Body Concept

The second configuration shown in Figure 2 was inspired by the extensive research now underway to develop a true Blended-Wing-Body (BWB) aircraft such as the Boeing X-48B. This aircraft concept is a significant departure from the first aircraft design shown in Figure 1. First of all, the turbofan engines are buried within the very thick wing root as the wing blends into the fuselage. Then, the exhaust discharges through high aspect ratio 2-D nozzles at the trailing edge of the vehicle. The intent is not only to produce thrust through this nozzle throughout the flight but to create increased flow circulation around the aircraft, generating additional lift.

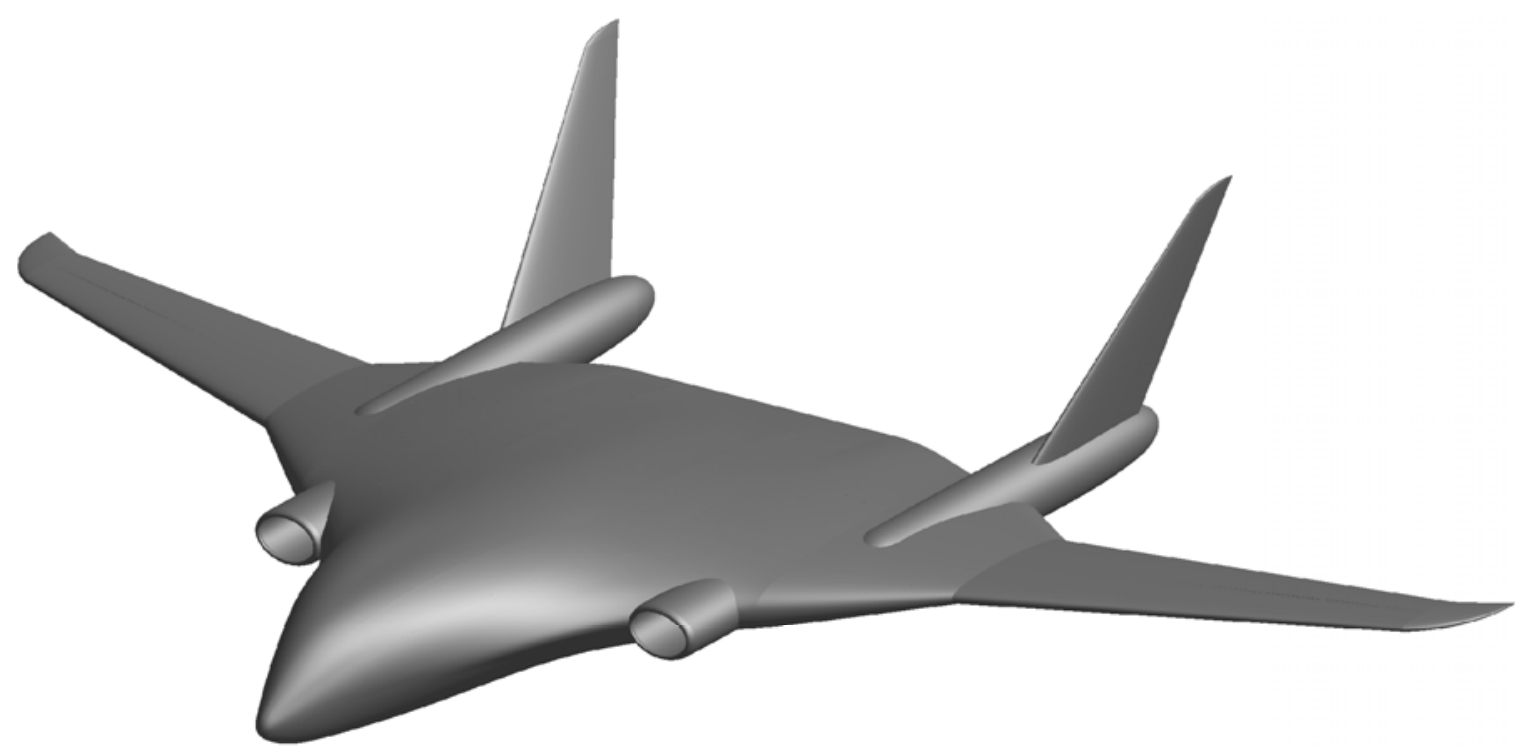

Figure 2: Blended Wing-Body Concept 
The final two years (Phase II) will be to design, construct, and test a full scale wind tunnel model of the CESTOL concept chosen from Phase I. The final objective of the contract is the development of predictive codes for these advanced powered-lift concepts and the generation of an open collection of computational and wind tunnel data that can be used by modelers to improve the capability of capturing these complex flows.

The use of CFD in designing a N+2 CESTOL concept is crucial. For these powered-lift configurations, traditional design methods break down because the aerodynamic performance of the wing is now integrated with the engine, the momentum coefficient, $\mathrm{C} \mu$ of the engine exhaust nozzles and/or slots. The slots can be seen in Figure 3. These all become a factor in the prediction of the lift coefficient. Phase II cannot begin until a calculated decision has been made on which configuration to continue forward with. Thus, it was decided at the beginning the of project that performing CFD on both configurations at takeoff and cruise conditions will provide the means to making a final decision for Phase I. Coupling the CFD analysis with the experimental analysis proposed for Phase II appears to be the best approach to meeting the objective of this project. The following sections discusses the methodologies and techniques used to generate the CFD data that helped determine the aircraft configuration to progress with in Phase II. All of the details of Phase I will not be included, but can be found in Ref [4].

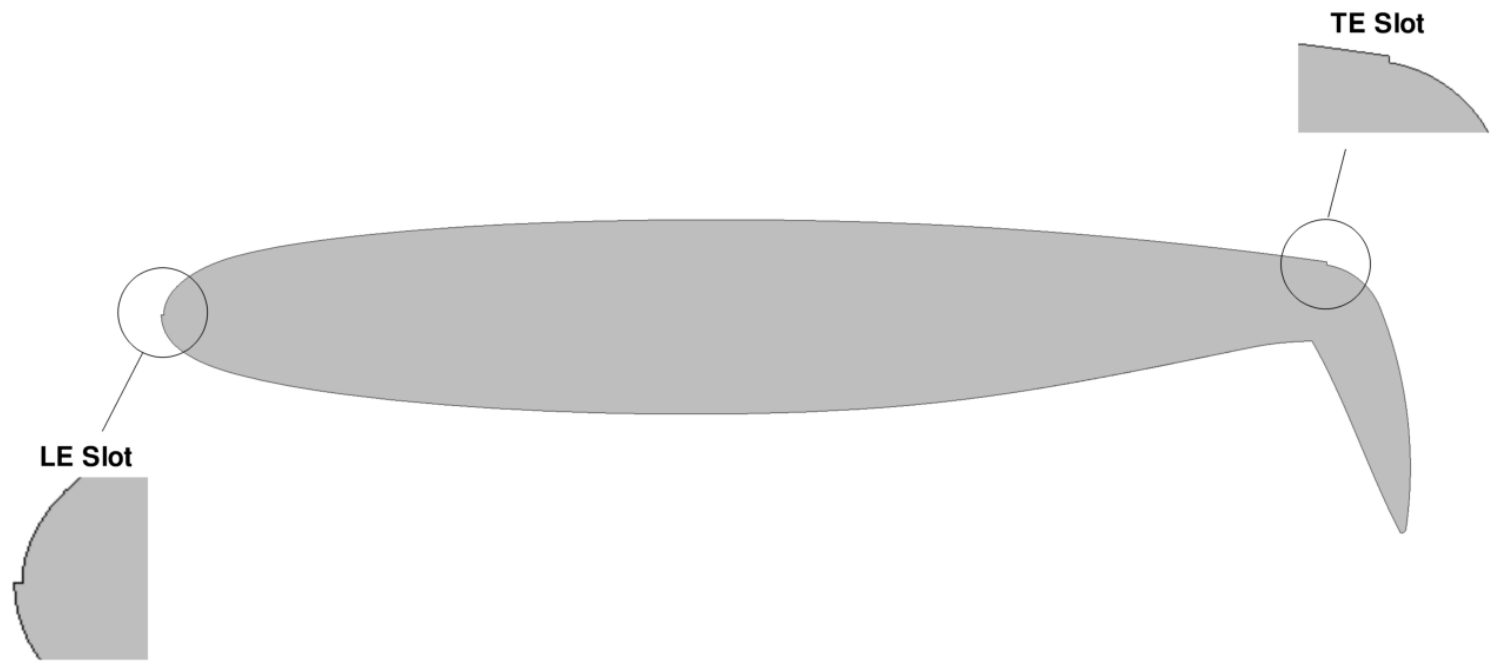

Figure 3: Takeoff configuration

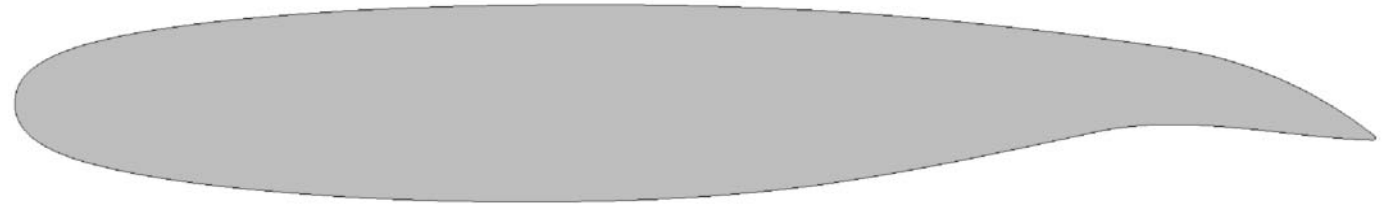

Figure 4: Cruise configuration 


\section{Grid Generating Methods}

The three step process to obtaining CFD results includes building a 3D model, generating a mesh around that model and then solving the governing equations of momentum, mass and energy in that mesh.

\section{A. CAD/Geometry}

Before meshing can begin, the geometry is generated within a computer aided drafting (CAD) software. Once finished it is then exported as a .step file that can be read into a grid generating software. The aircraft model is then broken up into different parts that will each vary in mesh size to allow for control of the mesh refinement on each surface so that a good quality mesh can be generated while still minimizing cell count. One thing to note is that yaw performance was not of interest in the first phase of the project. Thus, cell count can be further reduced by utilizing a symmetry boundary condition and only modeling half the aircraft as seen in Figure 5.

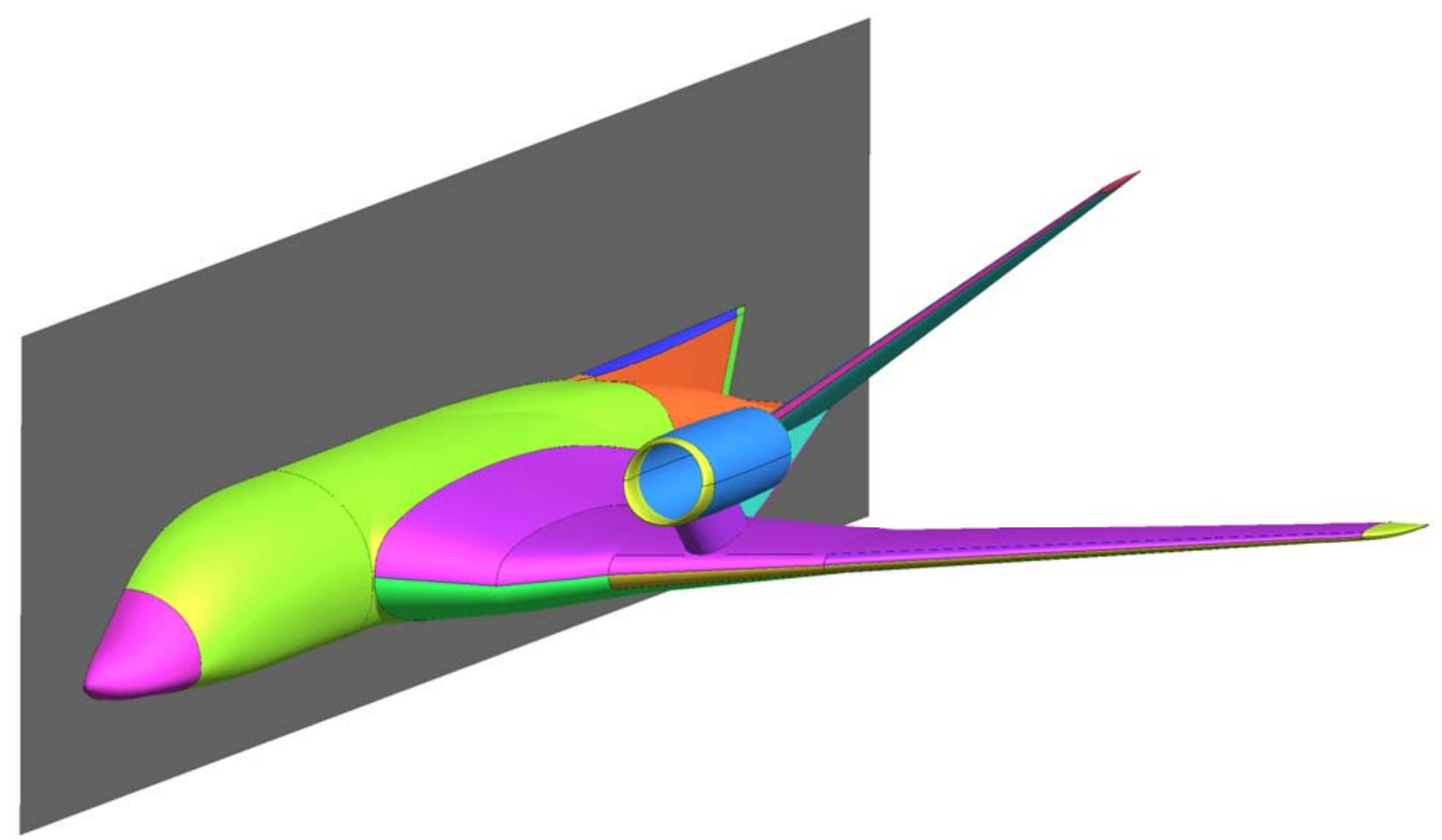

Figure 5: HWB concept split into manageable parts 


\section{B. Unstructured Surface Mesh}

Careful grid generation must be taken to ensure that the final mesh exhibits good quality elements. The quality of the mesh has significant implications on the convergence and stability of the numerical simulation and accuracy of the computational result obtained. The type of mesh chosen can determine the success or failure in attaining a computational solution. The mesh must be sufficiently fine to provide an adequate resolution of the important flow features and geometry topology. It is expected that simulating the HWB and BWB configurations will show recirculation vortices and steep flow gradients within the viscous boundary layer, thus requiring proper grid resolution. With air accelerating out of the trailing edge slot over the wing flaps, it is also expected that there will be high temperature gradients. Generating a high quality mesh that can capture all these important near wall flow characteristics first requires a high quality surface mesh. There are various ways to generating a high quality surface mesh. One can use all structured elements, all unstructured elements, or a combination of both. The grid generation software chosen for this NRA is ICEM CFD [1]. ICEM CFD has a built-in function that can automatically map out the entire geometry with unstructured triangle elements. For this reason alone, it was decided that all meshes generated will have a fully unstructured surface mesh. Doing so proved to be the quickest approach to generating the surface mesh while still maintaining high quality elements. ICEM CFD allows different mesh sizes to be applied to each surface of the aircraft model. Surfaces that do not present severe curvature, such as the fuselage, flat surfaces of the wing and the tail, were meshed with coarse elements. Surfaces that do present a lot of curvature, such as the leading edge and trailing edge of lifting surfaces are meshed with finer elements so that the topology of the geometry can be captured. Figure 6, 7, and 8 shows examples of how various mesh sizes were utilized in order to maintain control over total cell count.

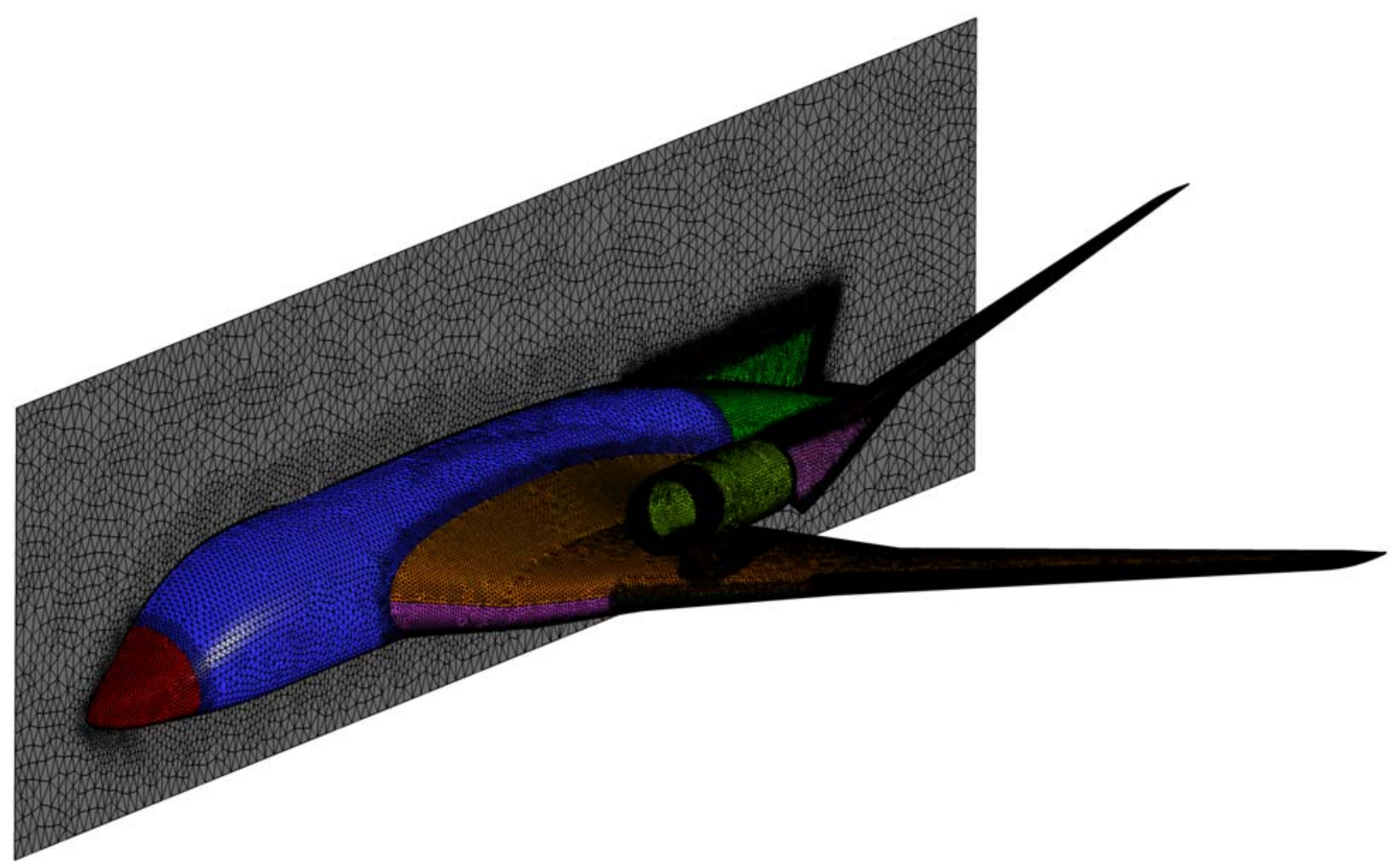

Figure 6: Surface meshing of the HWB concept 


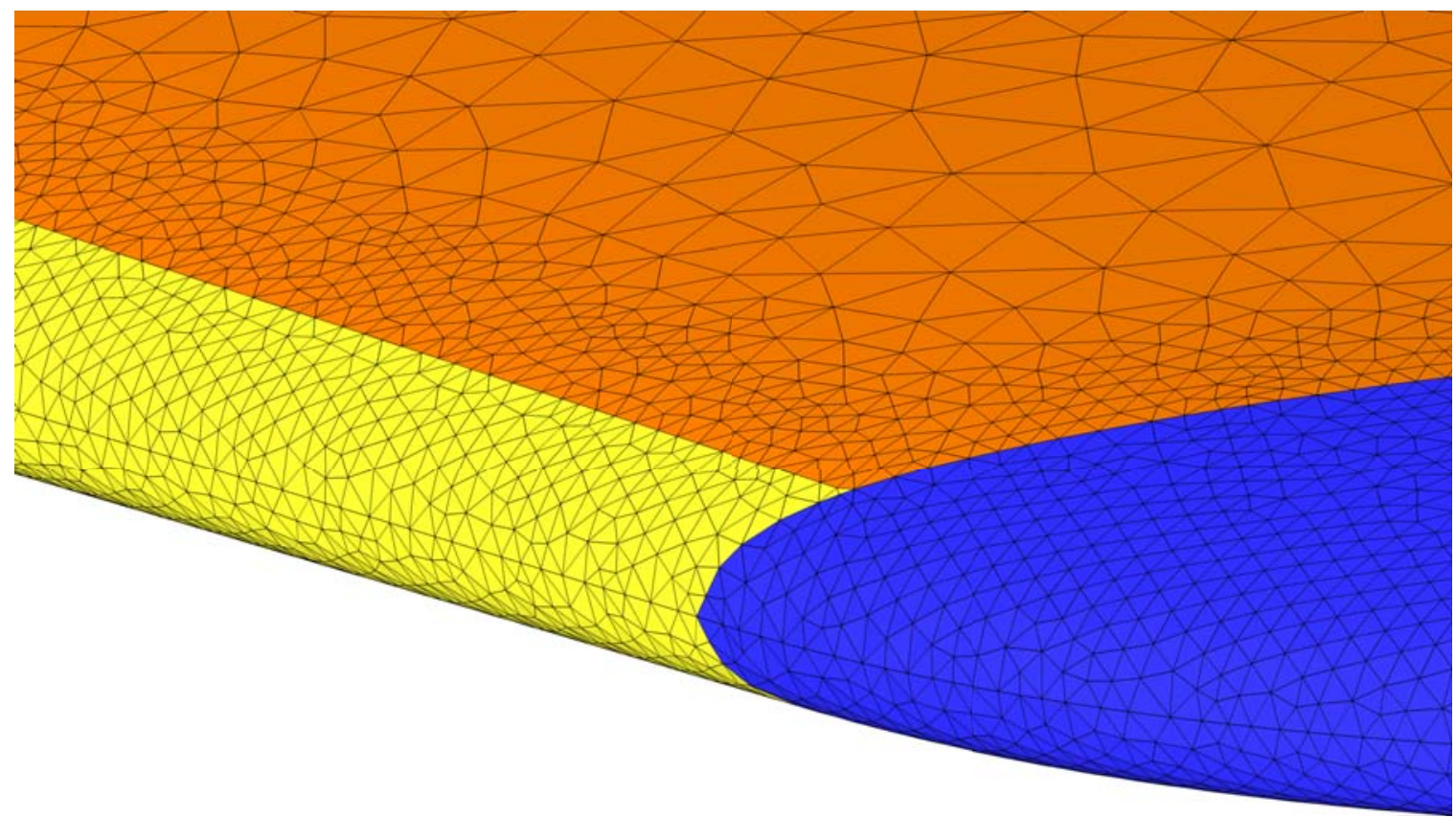

Figure 7: Surface meshing of the wing leading edge

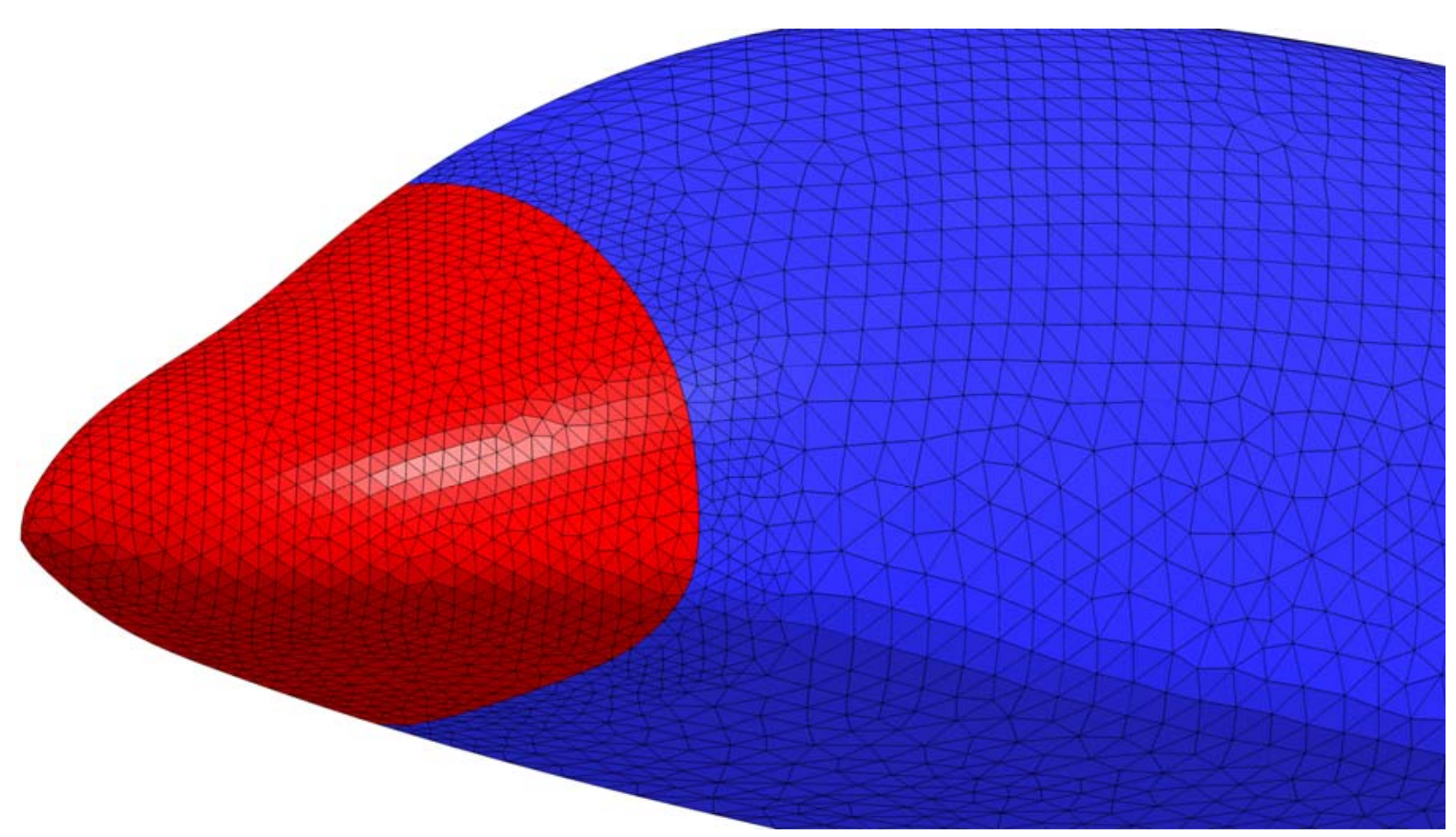

Figure 8: Surface meshing of the nose and fuselage 


\section{Boundary Layer Mesh}

It was mention previously that it is expected that the solution of the HWB and BWB configuration will exhibit several near wall flow features that need to be captured in order to ensure an accurate computational solution. There are several ways to modeling the near wall mesh. Whenever possible, the use of tetrahedral elements should be avoided in mapping out the mesh near the wall. With surface triangles, the use of prismatic elements would prove to be the most efficient choice. These shapes have the ability to adjust in accordance with the near-wall turbulence model requirements which will become an important issue in accurately capturing viscous effects.

Although it would be ideal to model the boundary layer to have at least one element within the viscous sublayer, the dramatic increase in cell count would warrant the mesh impractical and inefficient with existing resources. For most applications, it is acceptable to model the boundary to have at least one element within the fully turbulent loglaw layer and allow the solver to use wall functions to bridge the gap between the surface of the aircraft and the fully turbulent log-law layer. This wall function approach is the practical approach for generating solutions over the full plane configurations.

The high quality mesh that is desired will require careful consideration to cell shape in terms of aspect ratio, skewness, and warp angle. Prism elements are prone to showing poor qualities in these categories if care isn't taken. Elements with large aspect ratios should always be avoided in critical regions of the flow field. These type of elements can degrade the solution accuracy and may result in instability of the simulation. As for skewed elements, this will be inevitable. It is up to the user to maintain a low number of elements below a certain skewness quality. For complicated geometries such as the HWB and BWB, this will become very difficult. Most grid-generating packages have built-in smoothing algorithms that help remedy the complications expected to be seen in building prism elements on the aircraft.

There will be prisms, tetrahedral, and hexahedral volume elements used to model the domain. To ensure a good mesh, the user needs to consider volume transition ratio. For a good volume transition from the surface triangles to the volume elements, each prism element follows a maximum of $40 \%$ volume growth ratio. As for the interface between the prisms and tetrahedrals, the user should aim to have the last prism element be roughly 1:1 volume ratio to the adjacent tetrahedral element. Figure 9 shows an example of how prism elements are to be mapped for each surface of the aircraft model.

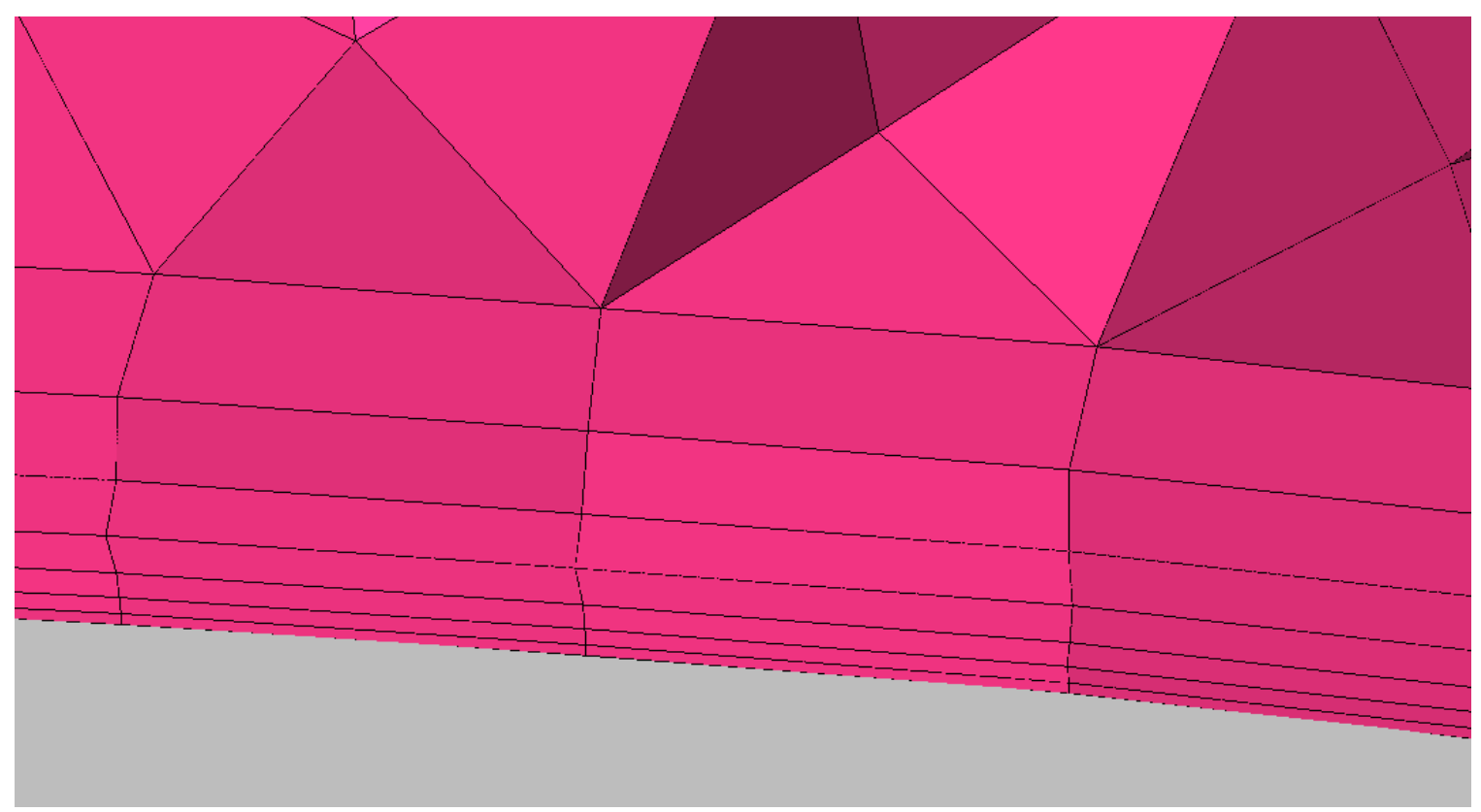

Figure 9: Prism layers grown off the surface of the HWB concept 


\section{Unstructured Volume Mesh}

E. Constructing a good mesh in the region near the aircraft will be important as it presents a lot of the unsteadiness that is expected to occur in the numerical simulation. The choice of which type of mesh to employ in this region will be of great concern. The user can utilize a fully structured or unstructured mesh. However, the use of a fully structured mesh would require that the surface mesh be also structured, which is not a trivial task. The application of a structured mesh for this problem has certain advantages and disadvantages. Computationally, it is much faster and contains less numerical error to handle hexahedral elements because of the way the solver is programmed. The hexahedral elements allow the CFD solver to obtain computational solutions much quicker than unstructured meshes. However, the disadvantages of adopting such a mesh for complex geometries increases grid nonorthogonality or skewness that can cause unphysical solutions. Solving skewed cells is much more computationally intensive as it requires solving additional terms in the discretized governing equations.

With the convenient option to use the automated unstructured meshing tool built in ICEM CFD, it was decided that near the aircraft body would embody unstructured tetrahedral elements. Tetrahedral elements are well suited for handling arbitrary shape geometries. This proves to be a major plus as the HWB and BWB geometries include high curvature boundaries. Employing unstructured tetrahedral meshing to the domain will inherently increase the total cell count because it has be to adequately fine enough to resolve the important flow features in that region. However, the ability to map out the domain automatically will prove to save more time in the long run, even though simulation time will increase due to the increase in cell count. In the future, structured meshes will be generated on the surface and domain in order to compare to the unstructured meshing technique employed for Phase I. The method used for constructing this portion of the mesh utilizes the Octree method [1]. This algorithm ensures refinement of the mesh where necessary, but maintains larger elements where possible, allowing for faster computation. In general, this method is considered top-down approach in that it begins by meshing the outer domain before capturing the surfaces of the geometry with elements. Figure 10 shows an example of how tetrahedral elements were automatically clustered. These elements extend adequately in all directions to be able to capture the highly unsteady flow regime that surrounds the aircraft.

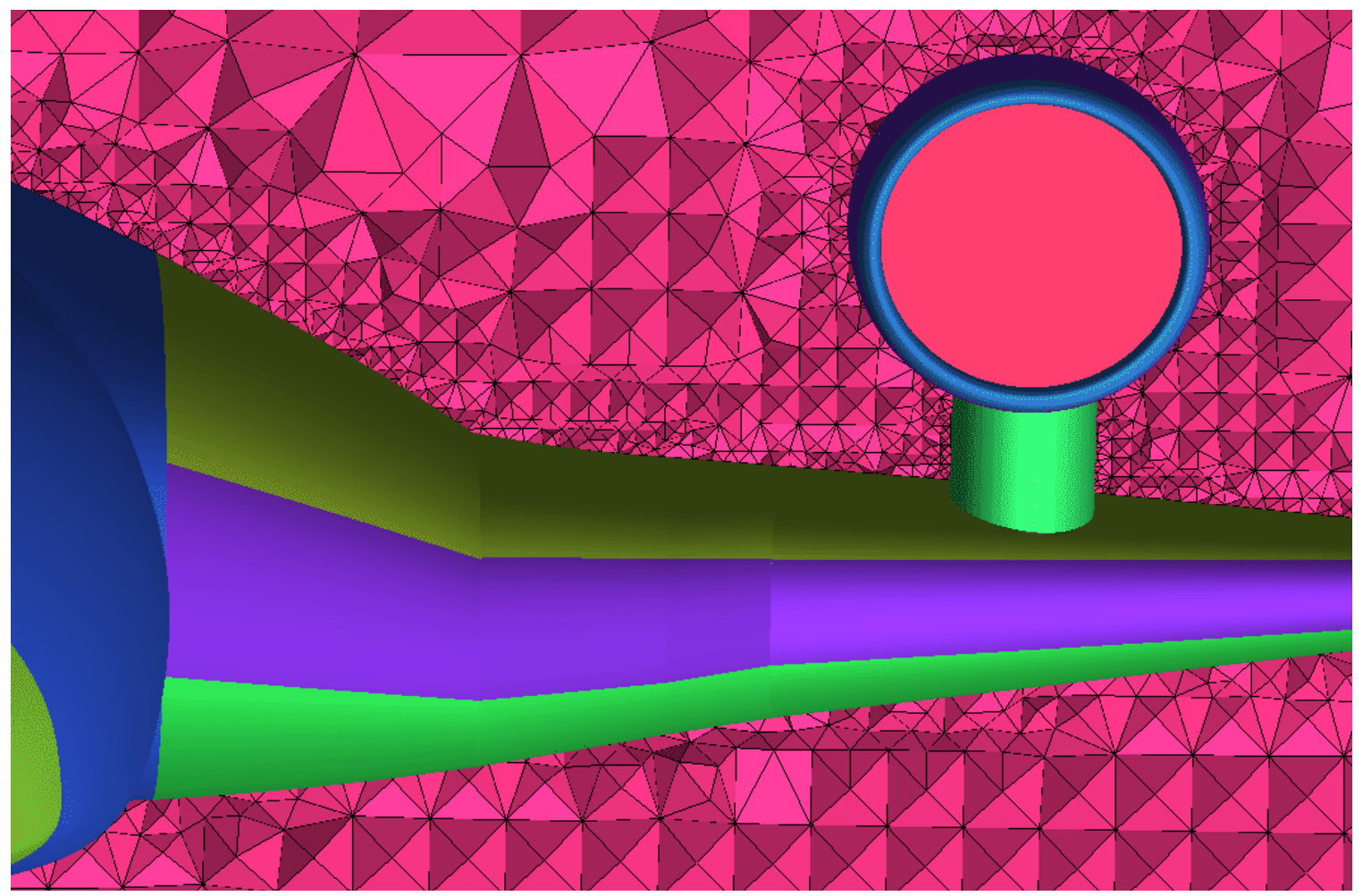

Figure 10: Unstructured interior volume mesh of HWB concept 


\section{F. Structured Exterior Volume Mesh}

To model the flow field that is away from the unsteady flow regime that surrounds the aircraft, hexahedral elements proved to be the most efficient way to capture the secondary flow features. The mesh was assembled using a number of structured blocks attached to each other. Using this multi-blocking approach gives the user a lot of flexibility in choosing how to map out each structured block. Perhaps the user wants to really refine a certain block but does not need the same grid resolution in a different box. For example, it is expected that the flow field will exhibit secondary flow features such as wingtip vortices. These vortices are known to travel well behind the aircraft before dissipating completely. In subsonic flow, failure to capture this feature accurately may greatly affect the final computational solution. Thus, it would be advised that the blocks that represent behind the aircraft be much more resolved. Figure 11 shows an example of what the blocking scheme looks like.

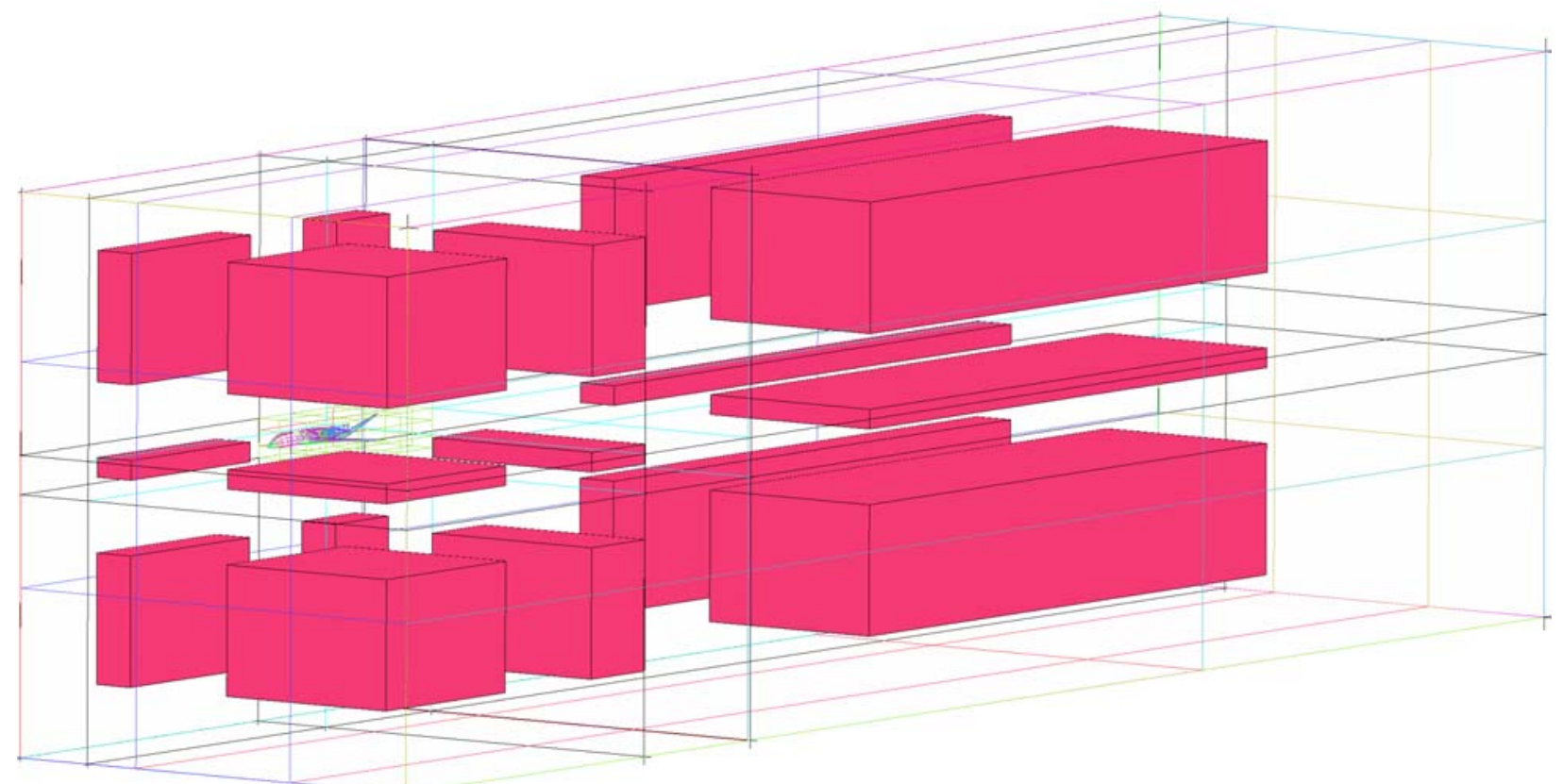

Figure 11: Multi-blocking scheme used to map structured exterior volume mesh

Instead of using hexahedral elements, the user could use unstructured tetrahedral elements to model this portion of the mesh. However, doing so would diminish the accuracy of the solution and would unnecessarily increase total cell count. Following general rules of thumb for grid generation, the structured domain was modeled to be roughly five airplane lengths upstream and; 4 plane length upward, downward and to the side of the aircraft. Downstream of the aircraft, however, structured elements extended out to ten airplane lengths. An example of the hybrid mesh used is shown for the HWB concept in Figure 12. 


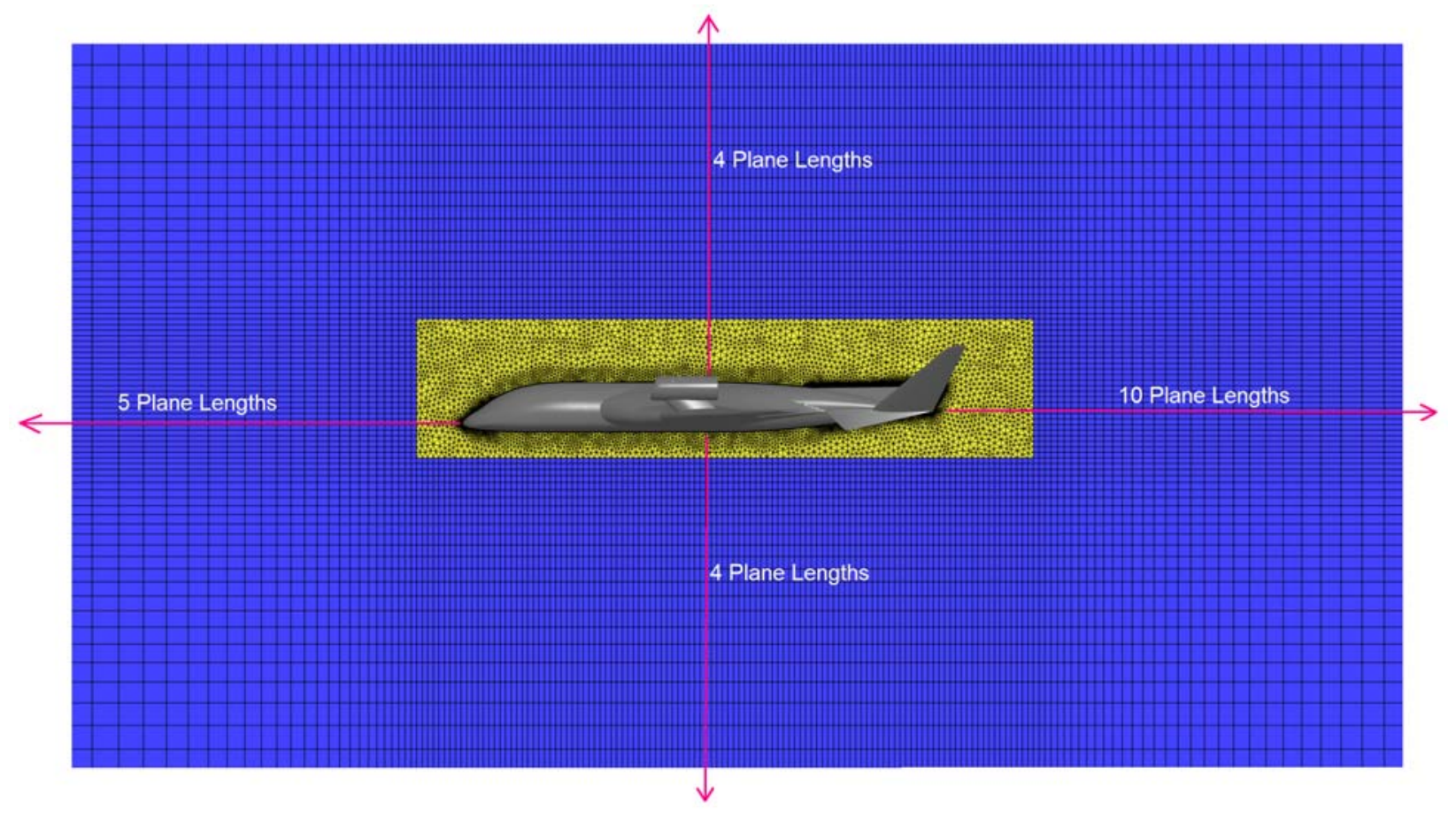

Figure 12: Hybrid meshing of the HWB concept

\section{Numerical Simulation Techniques}

The numerical scheme chosen for the 3D cases is an implicit compressible solver that couples and solves the governing equations of continuity, momentum, and energy simultaneously for each cell in the mesh. The coupled solver was developed for compressible flows and because the flow exiting from the leading and trailing edge slots is compressible, this solver proves to the solver choice.

Since most flows in aerospace applications are turbulent in nature, the classical two-equation modeling approach of handling turbulence was employed for all numerical simulations. A turbulence model is supposed to close the system of discretized governing equations. Nowadays, the two-equation modeling approach has formed the basis of turbulence calculations in numerous commercial and in-house CFD codes. At hand are several turbulence models that can be used to model turbulence in the problem. It is up to the user to carefully understand the flow characteristics expected in the flow field and to apply the appropriate turbulence model to capture those characteristics. The pressing choice of selecting a suitable turbulence model can be of great difficulty. The CFD code chosen for numerical simulation is Fluent [3]. Fluent has several turbulence models available to the user. However, for this project, three turbulence models were chosen to be of primary focus in choosing the best turbulence model; a one equation model called Spalart-Allmaras, and two, two-equation models, k- $\varepsilon$ and $k-\omega$. Performing 3-D analysis for various configurations for all three turbulence models would be too time consuming. It was decided that the best approach was to conduct a 2-D case study [4]. The study involved the simulation of a CCW airfoil and to compare it to existing experimental data. All three turbulence models were used to show which would be best to continue forward with for 3-D simulation and analysis. This 2-D case study concluded that $\mathrm{k}-\omega$ is the most accurate in capturing turbulence features in the CCW airfoil. However, it was not the quickest or most stable in obtaining convergence. On the other hand, Spalart-Allmaras demonstrated convergence the fastest although not the most accurate. The amount of time available left for Phase I started becoming a pressing issue, thus it was decided that continuing forward onto 3-D analysis with Spalart-Allmaras would be acceptable. Once solutions are obtained, it is important to ensure that expected flow features show up. Although not the most accurate, more emphasis was placed on the general understanding of what the flow field looks like around the HWB and BWB. The objective was that by capturing the general features of the flow field would hopefully yield a dominant configuration over the other. 
Near the surface of the aircraft, the boundary layer that develops can be subdivided into three layers as shown in Figure 13 from Fluent's Help Manual [3].

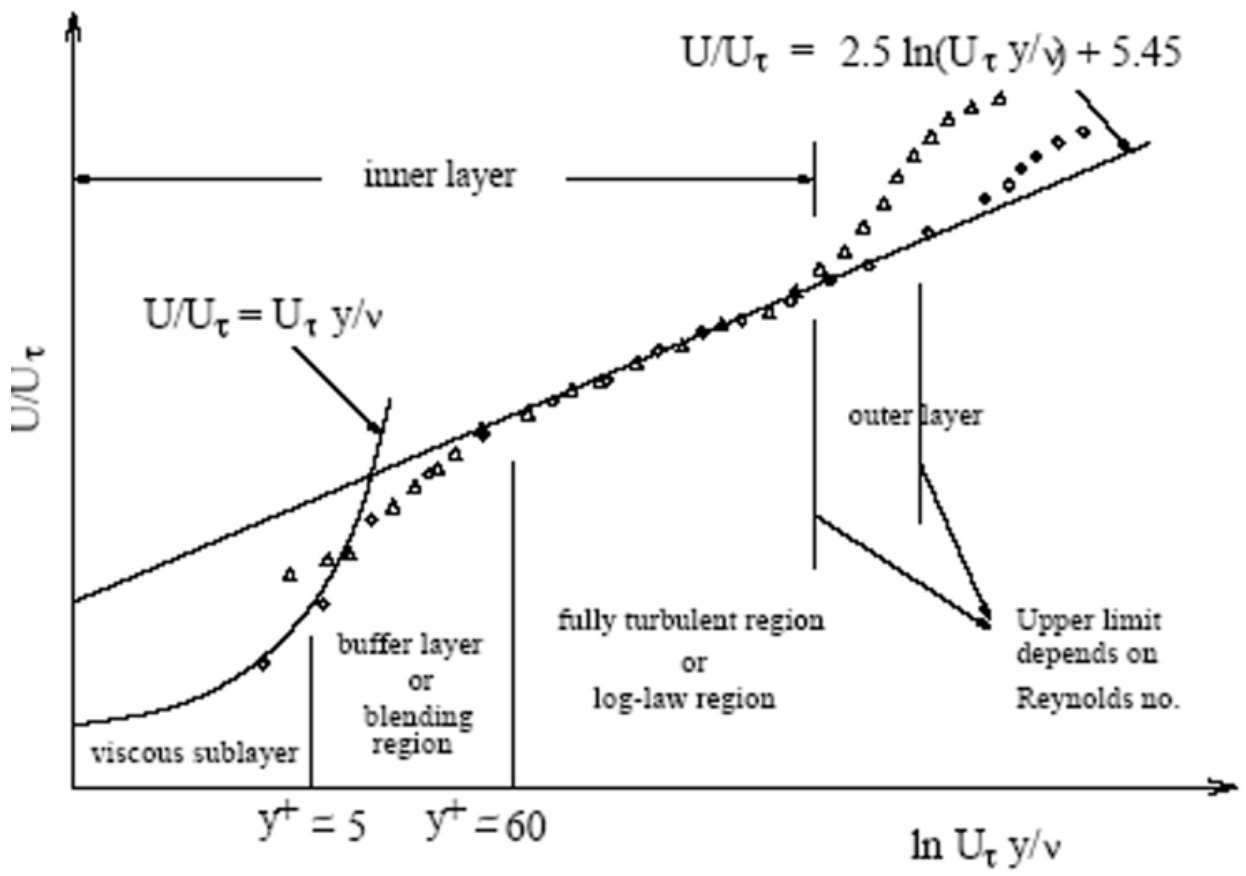

Figure 13: The three layers in the boundary layer from [3]

The general consensus of the CFD community is to never model any cells within the highly non-linear buffer layer. If the first prism layer has a $\mathrm{y}^{+}$within either the viscous sub layer or the fully turbulent region, then the boundary layer is considered accurately modeled. Fluent has two ways of modeling the boundary layer: 1 ). Wall Functions and 2). Near-Wall Treatment. Figure 6 from Fluent's Help Manual show the general idea of each approach toward modeling the boundary layer.

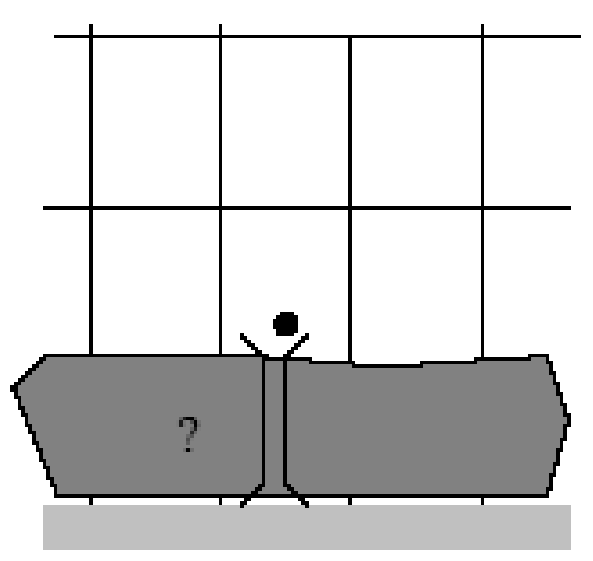

\section{Wall Function Approach}

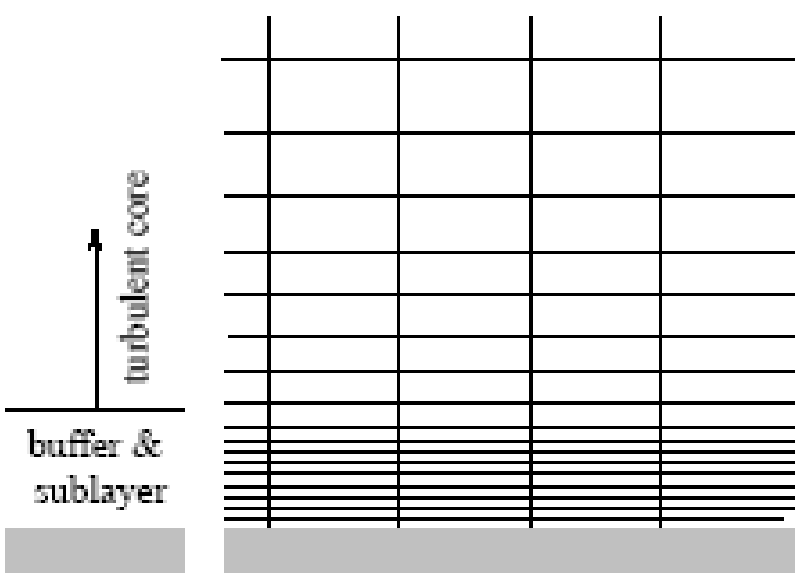

Near-Wall Model Approach

Figure 14: Two different approaches to obtaining an acceptable boundary layer from [3]. 
The use of the Near-Wall Model would not be a problem when analyzing 2D cases because cell count can be controlled very easily. However, for 3D cases with complex features such as leading and trailing edge slots, control over total cell count becomes a difficult task. Presently, existing resources would not be able to solve a very refined mesh.

On the other hand, semi-empirical formulas called "wall functions" could be used to bridge the surface of the aircraft model and the fully turbulent log-law region. This approach allows feasible meshes to be generated and could be solved in a timely manner with available resources. Using the wall function approach, all boundary layer cells must fall within the fully turbulent log-law region $\left(60<y^{+}<300\right)$ in order to assure an accurate boundary layer. Obtaining this level of accuracy requires multiple iterations of the mesh, thus confirming the need for quick preliminary results. With each solution, the modeling of boundary layers will become more accurate.

Another important feature to understand for this project are the boundary conditions applied to the flow field. The boundary conditions employed have serious implications on the computational solution. There will always be great difficulty in defining the correct boundary conditions to mimic the real physical representation of the flow field. Table 1 shows a detailed list of the solver settings and boundary conditions used for this project. The settings and boundary conditions used to generate the computational solutions thus far is by no means perfect. However, as will be shown later, the solutions obtained so far have illustrated reasonable results. With more time in the future, uncertainty analysis can be carried out to develop a good feel of the appropriateness and inappropriateness of the boundary conditions that are being imposed for the problem. 
Table 1: Solver Settings and Boundary Conditions for 3D Cases.

\begin{tabular}{|c|c|c|}
\hline & Cruise $(35,000 \mathrm{ft})$ & Takeoff \\
\hline Turbulence Model & Spalart-Allmaras & Spalart-Allmaras \\
\hline Solver & Compressible & Compressible \\
\hline Density Calculator & Ideal-gas Law & Ideal-gas Law \\
\hline Viscosity Calculator & Sutherland's Law & Sutherland's Law \\
\hline Freestream Boundary Condition & Pressure Far-Field & Pressure Far-Field \\
\hline Engine Inlet & Pressure Outlet & Pressure Outlet \\
\hline Engine Outlet & Mass Flow Inlet & Mass Flow Inlet \\
\hline CCW exit & N/A & Mass Flow Inlet \\
\hline Turbulence Specification Method & Turbulent Viscosity Ratio & Turbulent Viscosity Ratio \\
\hline Freestream Pressure (Psi) & 3.41 & 14.70 \\
\hline Freestream Density $(\mathrm{lbs} / \mathbf{f t} \wedge$ 3) & 0.0231 & 0.0765 \\
\hline Freestream Viscosity (slugs/ft-s) & 0.376 & 0.300 \\
\hline Freestream Velocity (ft/s) & 795.3 & 167.3 \\
\hline Freestream Mach Number & 0.8 & 0.15 \\
\hline Freestream Temp(R) & 411.7 & 518.4 \\
\hline Reference Length (ft) & 100.1 & 100.1 \\
\hline Reference Area $\left(\mathrm{ft}^{\wedge} \mathbf{2}^{2}\right)$ & 2136 & 2136 \\
\hline Engine Inlet Pressure (Psi) & 5.22 & 13.96 \\
\hline Engine Inlet Mass Flow Rate (slug/s) & 24.59 & 23.43 \\
\hline Engine Inlet Temp (R) & 443.3 & 518.7 \\
\hline Engine Outlet Pressure (Psi) & 6.99 & 20.45 \\
\hline Engine Outlet Mass Flow Rate (slugs/s) & 24.58 & 18.23 \\
\hline Engine Outlet Temp (R) & 566.1 & 695.9 \\
\hline LE CCW Pressure (Psi) & N/A & 27.5 \\
\hline LE CCW Mass Flow Rate (slugs/s) & N/A & 2.24 \\
\hline LE CCW Temp (R) & N/A & 529.2 \\
\hline TE CCW Pressure (Psi) & N/A & 27.5 \\
\hline TE CCW Mass Flow Rate (slugs/s) & N/A & 2.95 \\
\hline TE CCW Temp (R) & N/A & 529.2 \\
\hline
\end{tabular}




\section{Results \& Discussion}

\section{A. Choosing a Configuration}

Part of the decision process in choosing an aircraft configuration includes being able to have aerodynamic evaluations that can compare the two aircraft's aerodynamic properties to each other. It was decided that evaluations of the two aircraft configurations would be made at both takeoff and cruise conditions. This seemed to be a fair preliminary evaluation of the entire flight envelope that will be investigated on the chosen aircraft in Phase II. It was chosen to evaluate both takeoff configurations at 30 degree flap deflections and at a cruise conditions of Mach 0.8. For a sanity check on the lift and drag approximations they will be compared to DATCOM [2] a US Air Force Stability and Control software. These predictions were performed by DHC Engineering, Inc. Later in the project the computational methods will be compared to a wind tunnel test of the finalized configuration.

\section{a). HWB at Takeoff Conditions}

First, the HWB showed excellent aerodynamic characteristics in both cruise and takeoff conditions. The plane was modeled for takeoff at standard sea level conditions at Mach 0.2 with a $0^{\circ}$ angle of attack. The flap is deflected to $30^{\circ}$ from the horizontal and the leading and trailing edge slots are open. Figure 15 shows the isometric view of pressure coefficient over the surface of the airplane.
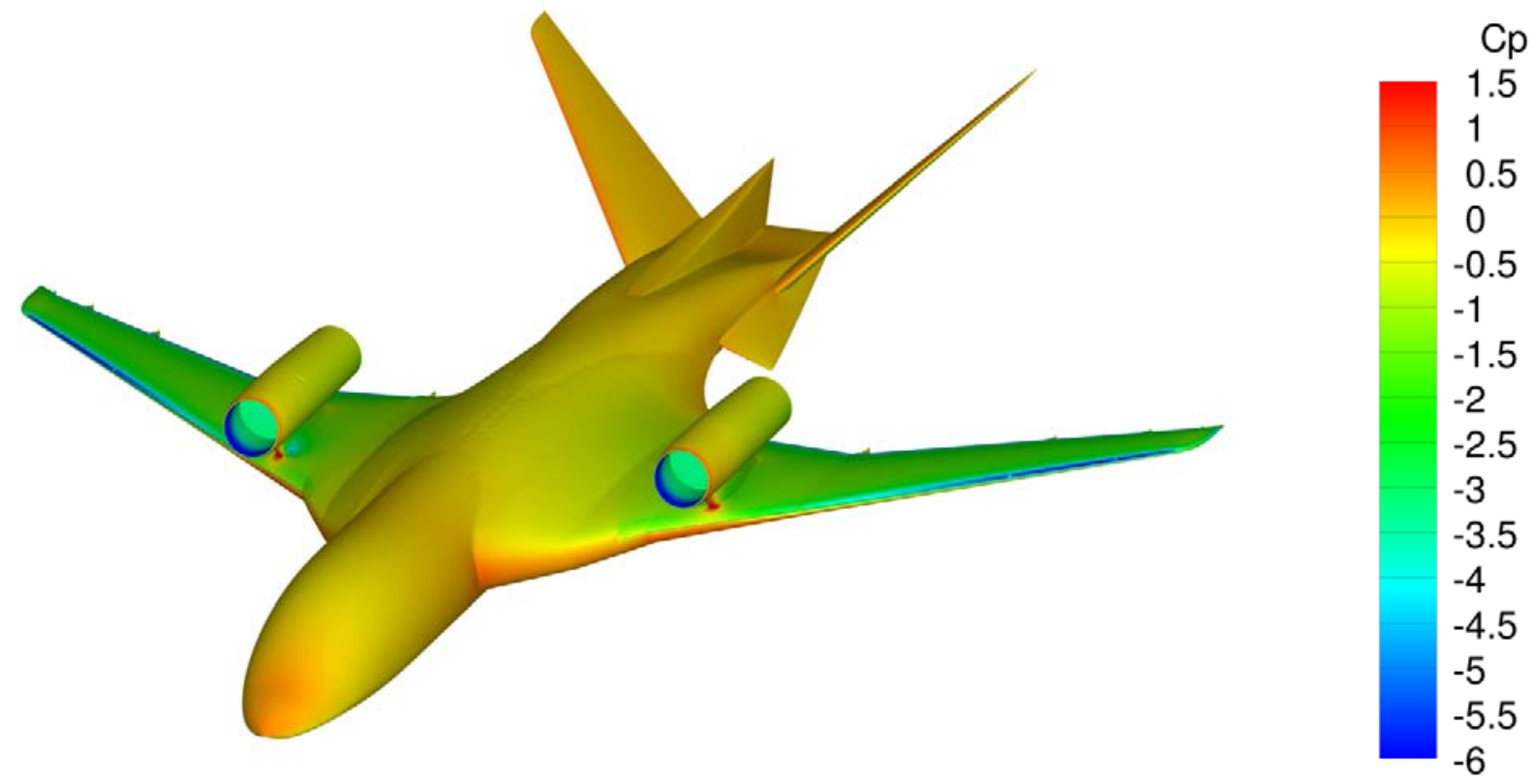

Figure 15: Pressure coefficient on the surface of the HWB aircraft at takeoff conditions.

HWB has leading edge and trailing edge CCW slots which provide for added lift. The performance numbers from the CFD results are given along with the design predicted numbers in Table 2. It can be seen that the lift-todrag of HWB is higher than predicted. This is most likely an effect of the increased lift from the CCW that may not have been accurately modeled in the design prediction method.

\begin{tabular}{|c|c|c|}
\hline & $\begin{array}{c}\text { CFD } \\
\text { Results }\end{array}$ & $\begin{array}{c}\text { Design } \\
\text { Predictions }\end{array}$ \\
\hline Lift Coefficient & 1.086 & 1.97 \\
\hline Drag Coefficient & 0.132 & 0.287 \\
\hline Lift-to-Drag Ratio & 8.24 & 6.86 \\
\hline
\end{tabular}


The most noticeable aerodynamic effect is how the streamlines flow downward at the trailing edge as Seen in Figure 16. This is due to the exhaust from the trailing edge slot that blows along the upper surface of the flap due to the Coanda effect. The energy of this exhaust is enough to pull the free stream flow downward and in the same direction of the exhaust. This helps performance for takeoff because it increases the virtual camber of the plane. Also, the flow is propagating more than a plane length downward showing the need for a large wind tunnel to accommodate the airflow from the large-scale wind tunnel model. This turned out to be a strong driver during the selection of the wind tunnel.

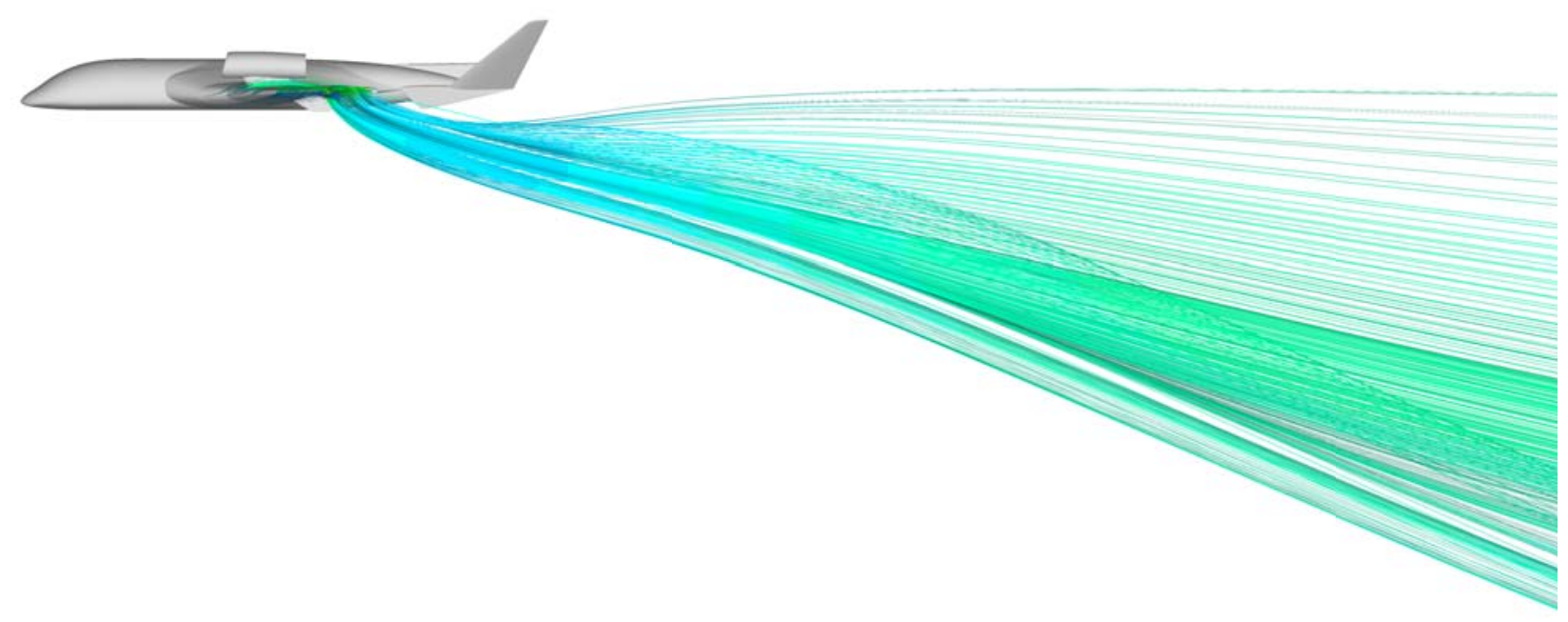

Figure 16: Streamlines over HWB at takeoff conditions.

b). HWB at Cruise Conditions

The CFD predictions for cruise conditions of Mach 0.8 at 35,000 feet showed promising results and its pressure coefficient is represented in Figure 17.

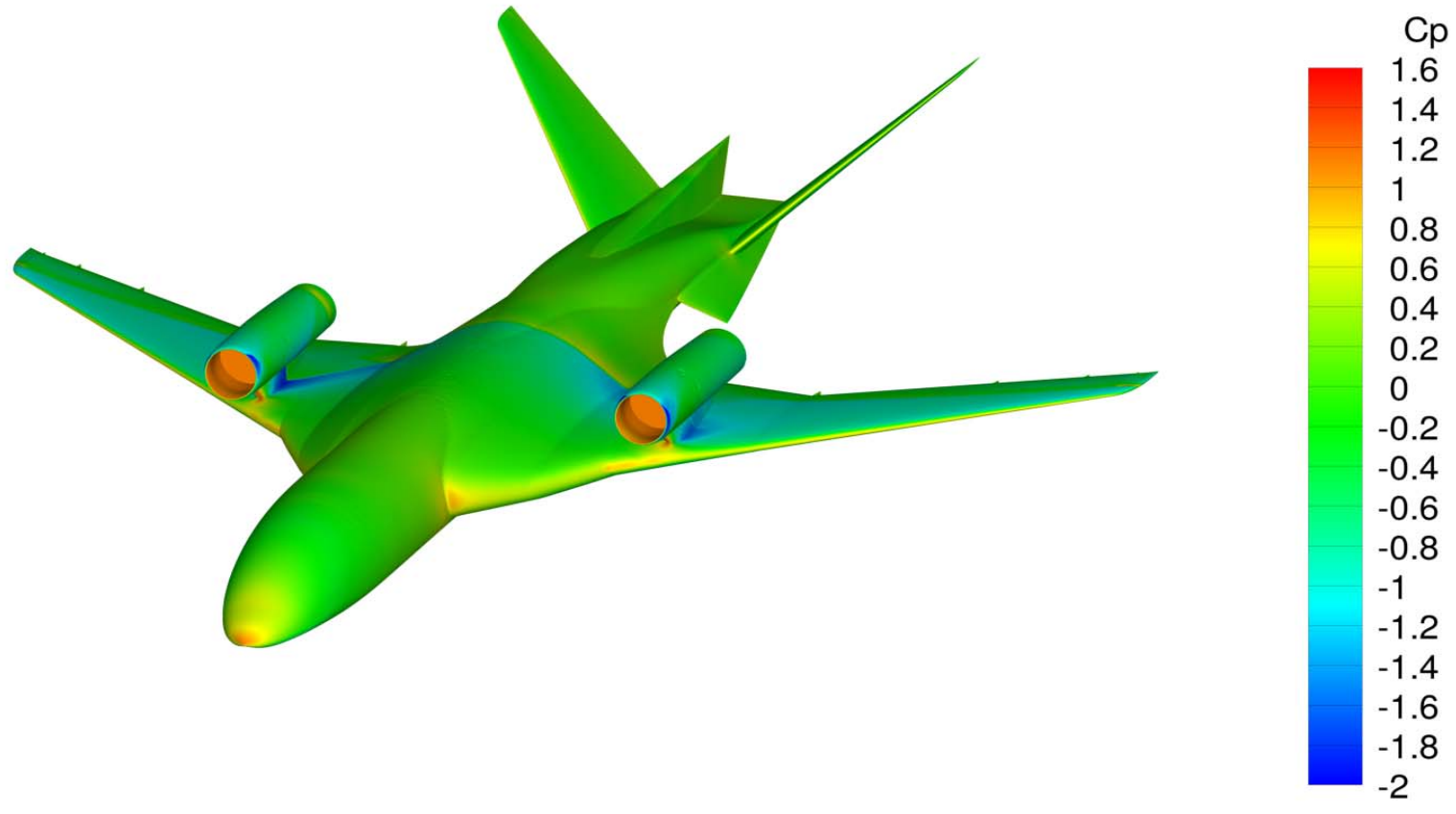

Figure 17: Pressure coefficient contours over HWB at cruise conditions. 
On the top surface a lowering in pressure halfway between the tip and tail can be seen. This shows the sudden increase in velocity over the surface which results in a normal shock slowing the flow from supersonic to subsonic speeds. The shock line is clearly visible in the pressure coefficient contours. As CFD analysis becomes more indepth, a better understanding will be gained so that the shape of the airfoil can be optimized in a way that will diminish the strength of the shocks as much as possible. Table 3 shows the performance results for HWB at cruise conditions. Figures 18 and 19 show the similarity between the 2D and 3D CFD results.

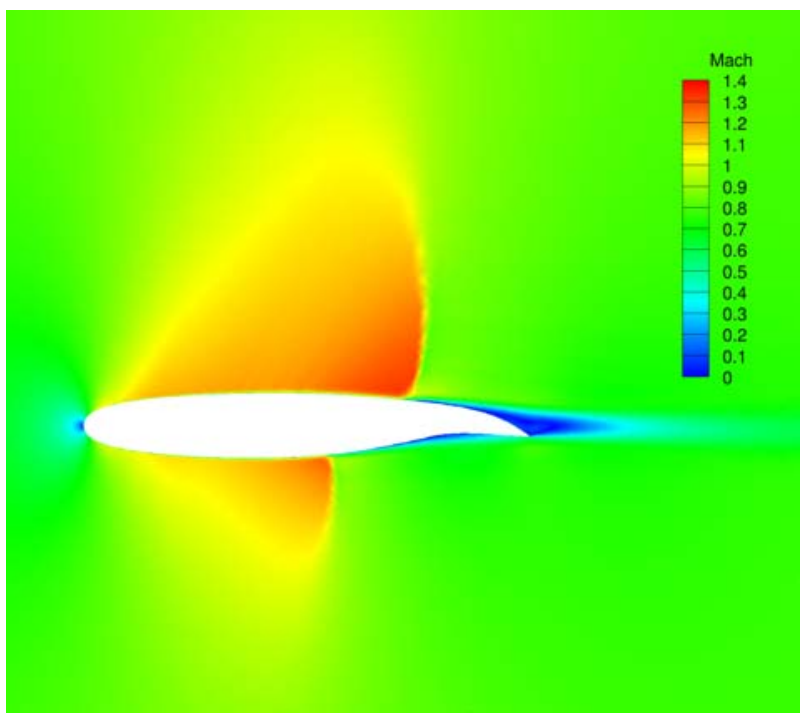

Figure 18: Mach contours of the 2-D airfoil chosen.

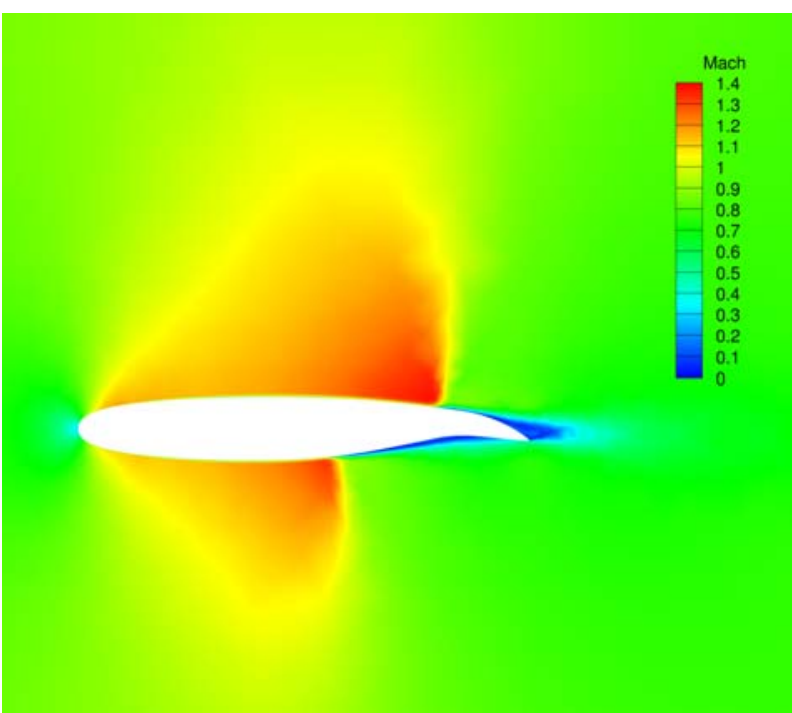

Figure 19: Mach contours of a 2-D slice of the 3-D wing of the HWB.

The results from the preliminary study of flap designs provided a starting point for creating the 3-D configurations. As can be seen in Figure 18, the performance of the 3-D case is similar to that of the 2-D case. The shock on both upper and lower surfaces appear to be similar in both strength and location. Checks like these often provide sanity checks so that we know the CFD is providing consistent and reasonable results. Some important things to note are that the shocks and shock-induced separation for the 3-D case are not resolved as well as the 2-D case. The shock could be more clearly defined by clustering more cells into these regions. Since, coarser cells were used in the 3-D mesh for the purpose of maintaining a low total cell count so that solutions could be obtained in a reasonable time frame, this smeared shock can be expected. In the future 3-D grid adaption will be investigated in order to resolve flow features such as shocks and regions of separation.

It can be seen that the lift-to-drag of the HWB at cruise is about $50 \%$ better than that of the predicted results. This could be due to many factors including but not limited to the highly unpredictable transonic effects captured by the CFD and not by the predicted equations.

Table 3: Performance results for HWB at cruise.

\begin{tabular}{|r|c|c|}
\cline { 2 - 3 } \multicolumn{1}{c|}{} & $\begin{array}{c}\text { CFD } \\
\text { Results }\end{array}$ & $\begin{array}{c}\text { Design } \\
\text { Predictions }\end{array}$ \\
\hline Lift Coefficient & 0.237 & 0.191 \\
Drag Coefficient & 0.015 & 0.019 \\
Lift-to-Drag Ratio & 15.89 & 10.16 \\
\hline
\end{tabular}


c). BWB at Takeoff Conditions

The BWB was also simulated at takeoff of Mach 0.2 and standard sea level conditions. The flap behind the engine exhaust is at a $30^{\circ}$ deflection from the horizontal. Figure 20 shows the pressure coefficient over the surface of the airplane.

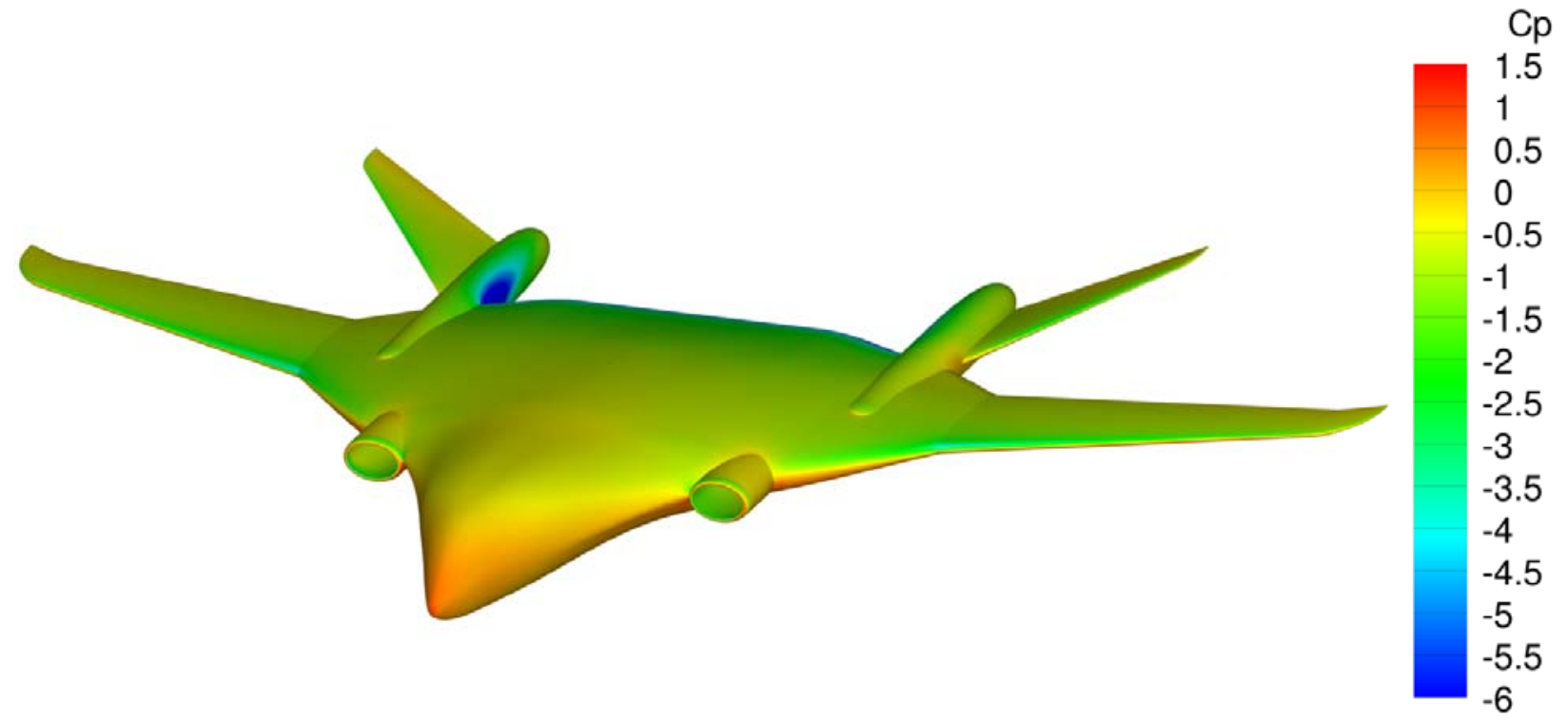

Figure 20: Pressure coefficient over the surface of BWB at takeoff conditions.

BWB yielded performance results as seen in Table 4. BWB has good lift for takeoff due to the blended wing body design. However, the drag is also very high which provides for a fairly low lift-to-drag ratio.

Table 4: Performance results for BWB at takeoff.

\begin{tabular}{|r|c|c|}
\cline { 2 - 3 } \multicolumn{1}{c|}{} & $\begin{array}{c}\text { CFD } \\
\text { Results }\end{array}$ & $\begin{array}{c}\text { Design } \\
\text { Predictions }\end{array}$ \\
\hline Lift Coefficient & 2.03 & 3.21 \\
Drag Coefficient & 0.70 & 0.70 \\
Lift-to-Drag Ratio & 2.90 & 4.992 \\
\hline
\end{tabular}




\section{d). BWB at Cruise Conditions}

The isometric view of the pressure coefficient distribution of the BWB under cruise conditions is shown in Figure 21.

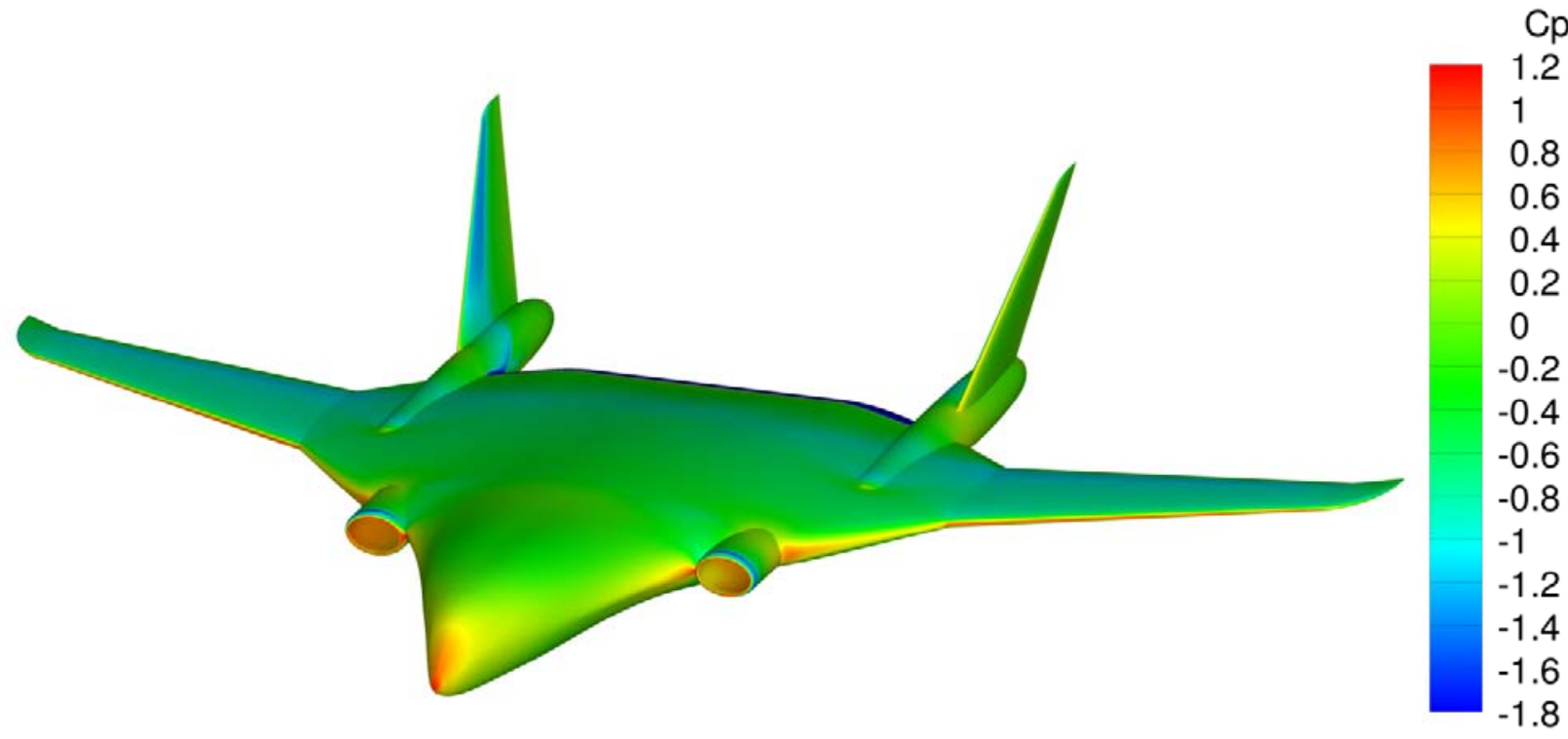

Figure 21: Pressure coefficient distribution over the surface of the BWB.

The same aerodynamic properties seen on the HWB can be seen here. Something similar to the shock wave seen on the HWB appears on BWB. A shock can clearly be see on the inside surface of the vertical tail. This shock becomes an issue because of the loss in controllability from the shock induce separation. It shows the need to sweep back the tail more to reduce the shock on the tail surface.

The performance numbers from this takeoff simulation are shown in Table 5. It can be seen that the lift-to-drag results from CFD analysis are worst than the predicted design numbers. The inaccurate prediction of drag could be a result of numerous errors. One of which could be how well the boundary layer was modeled. As stated previously, wall functions were used for all 3D simulations. This requires that all boundary layers contain at least one cell within the fully turbulent log-law region $\left(60<y^{+}<300\right)$. Some portions of the solution presented above did not meet this requirement. Also the shock on the tail would not have been predicted in the DATCOM method so this would result in a higher drag coefficient in the CFD solution.

Table 5: Performance results of $B W B$

\begin{tabular}{|r|c|c|}
\multicolumn{1}{c|}{ at cruise. } \\
\cline { 2 - 3 } \multicolumn{1}{c|}{$\begin{array}{c}\text { CFD } \\
\text { Results }\end{array}$} & $\begin{array}{c}\text { Design } \\
\text { Predictions }\end{array}$ \\
\hline Lift Coefficient & 0.41 & 0.121 \\
Drag Coefficient & 0.07 & 0.015 \\
Lift-to-Drag Ratio & 5.78 & 8.35 \\
\hline
\end{tabular}




\section{e). Summary of Results}

A look at the performance results for both configurations at cruise and takeoff are given in Table 6. As can be seen in Table 6, the HWB performs better at both cruise and takeoff. The HWB has 184\% better lift-to-drag at takeoff and approximately $175 \%$ better lift-to-drag at cruise than the BWB. This is due mainly to the greater drag on the BWB. At cruise, the engine outlet of the BWB flows over the flap which increases the friction or scrub drag on that patch tremendously. Overall, CFD results show that the HWB has better performance and will therefore be a better selection than the BWB. For this and other reasons the HWB was selected for the next phase of the project.

Table 6: Performance numbers for both configurations at takeoff and cruise.
\begin{tabular}{|c|c|c|c|c|c|c|}
\hline \multicolumn{7}{c|}{ Takeoff } \\
\hline & \multicolumn{7}{c|}{ CFD Results } & \multicolumn{3}{c|}{ Design Predictions } \\
\cline { 2 - 8 } & $\mathbf{C}_{\mathbf{L}}$ & $\mathbf{C}_{\mathbf{D}}$ & L/D & $\mathbf{C}_{\mathbf{L}}$ & $\mathbf{C}_{\mathbf{D}}$ & L/D \\
\cline { 2 - 8 } Hybrid-BWB & 1.09 & 0.132 & 8.24 & 1.97 & 0.287 & 6.86 \\
BWB & 2.03 & 0.70 & 2.90 & 3.21 & 0.643 & 4.99 \\
\hline \multicolumn{7}{|c|}{ Cruise } \\
\hline Hybrid-BWB & 0.237 & 0.015 & 15.89 & 0.191 & 0.019 & 10.16 \\
BWB & 0.41 & 0.07 & 5.78 & 0.121 & 0.015 & 8.35 \\
\hline
\end{tabular}

\section{B. Verification Assessment}

Generating high quality meshes and computational solutions are both necessary, but not sufficient in attaining credibility. It is extremely important that the user understand the role that verification plays in the success of employing CFD. The "correct answer" can only be known in a relatively small number of isolated cases, thus the process of simulating complex models will always introduce error. It is the user's responsibility to be able to estimate and quantify all sources of error that may exist in the computational solution. This can be done through verification assessment. Verification assessment can be viewed as the process that minimizes any belief that are errors in the code or computational solution. This assessment is divided into two categories; code verification and solution verification. Code verification is certainly necessary, but will not be conducted until Phase II. The remainder of this section will present the results of solution verification. Solution verification is important because it identifies the discretization error associated with the numerical solution. There are two sources of solution errors; truncation error and discretization error. The process at which code-implementers approximate the governing equations will inherently introduce truncation error. On the other hand, discretization error is introduced by the solution of the discretized equations when compared to the exact solution to the governing equations. The role of discretization error in our considerations of solution verification is best described in terms of the following questions that must be answered.

- Does the numerical solution converge to the exact solution as the mesh spacing is reduced?

- What is the effective order of accuracy of the discretization that is actually observed in calculations?

- What is the discretization error that is actually observed for real calculations on finite grids?

To be able to answer these questions, the user must demonstrate iterative convergence and grid convergence for complete solution verification. Thus, the overall objective is to gather enough evidence to show that the computational solution is correct and accurate. 


\section{a). Iterative Convergence}

Almost all CFD codes calculate the successive iteration of steps of the entire flow field of the problem. The user must ensure that numerical simulation continues until the solution demonstrates iterative convergence, meaning the variable of interest no longer changes by some specified tolerance as each iteration of the flow field is computed. Most often, CFD users will monitor the residual error of the solution as a means of considering iterative convergence. The residual vector is the error in the present solution iteration as compared to the previous solution iteration. For simulations run on the HWB and BWB, this would require the monitoring of all discretized governing equations. However, it is considered more reliable to determine iterative convergence based on the variables of interest. In this case, the lift and drag coefficient of the aircraft. Monitoring the iterations of these two variables will ensure that the final result are fully converged in all aspects. Figure 22 and 23 shows the monitoring of iteration steps for lift coefficient and drag coefficient of one of many numerical simulations conducted for this project.

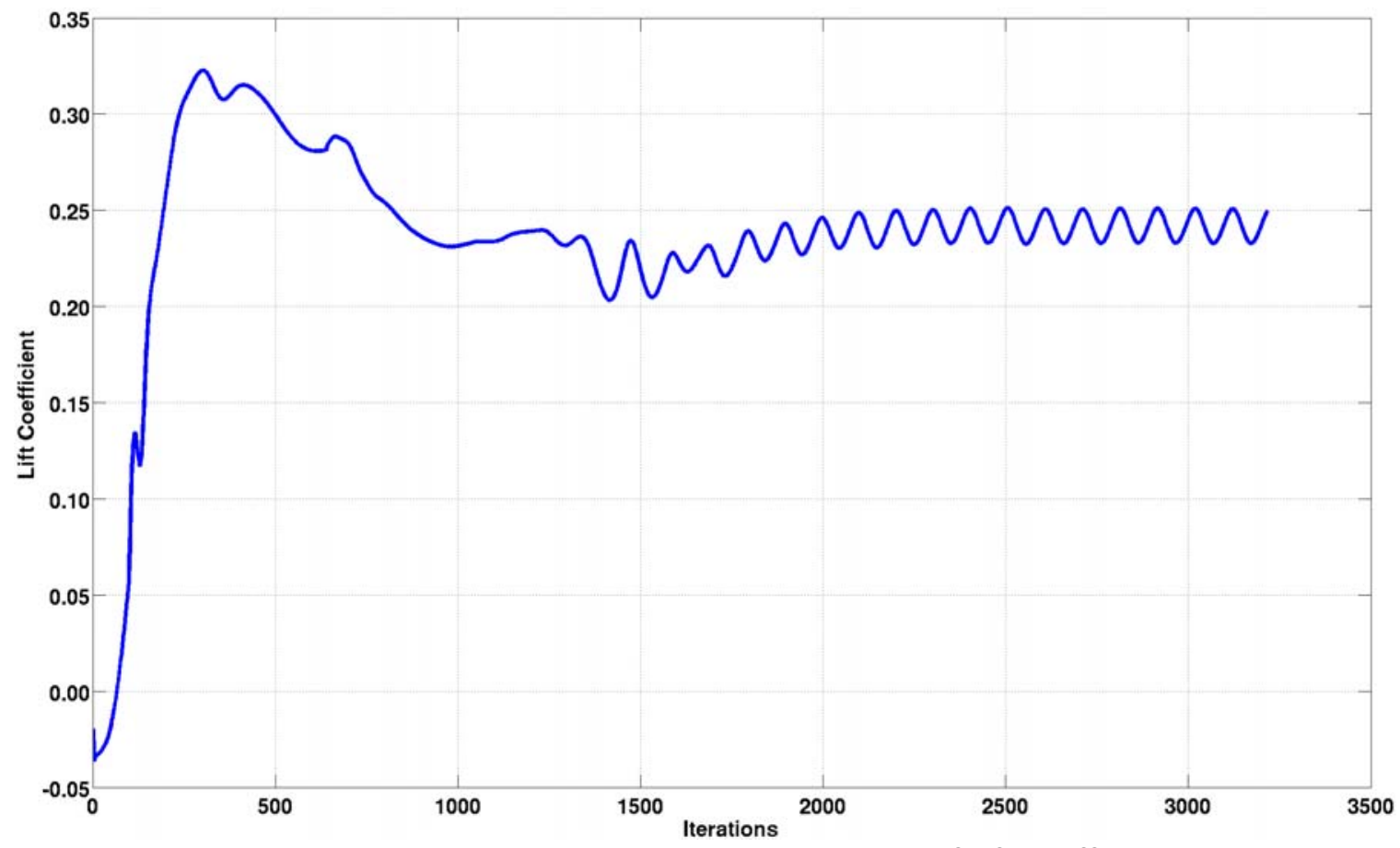

Figure 22: Iterative convergence monitoring of lift coefficient 


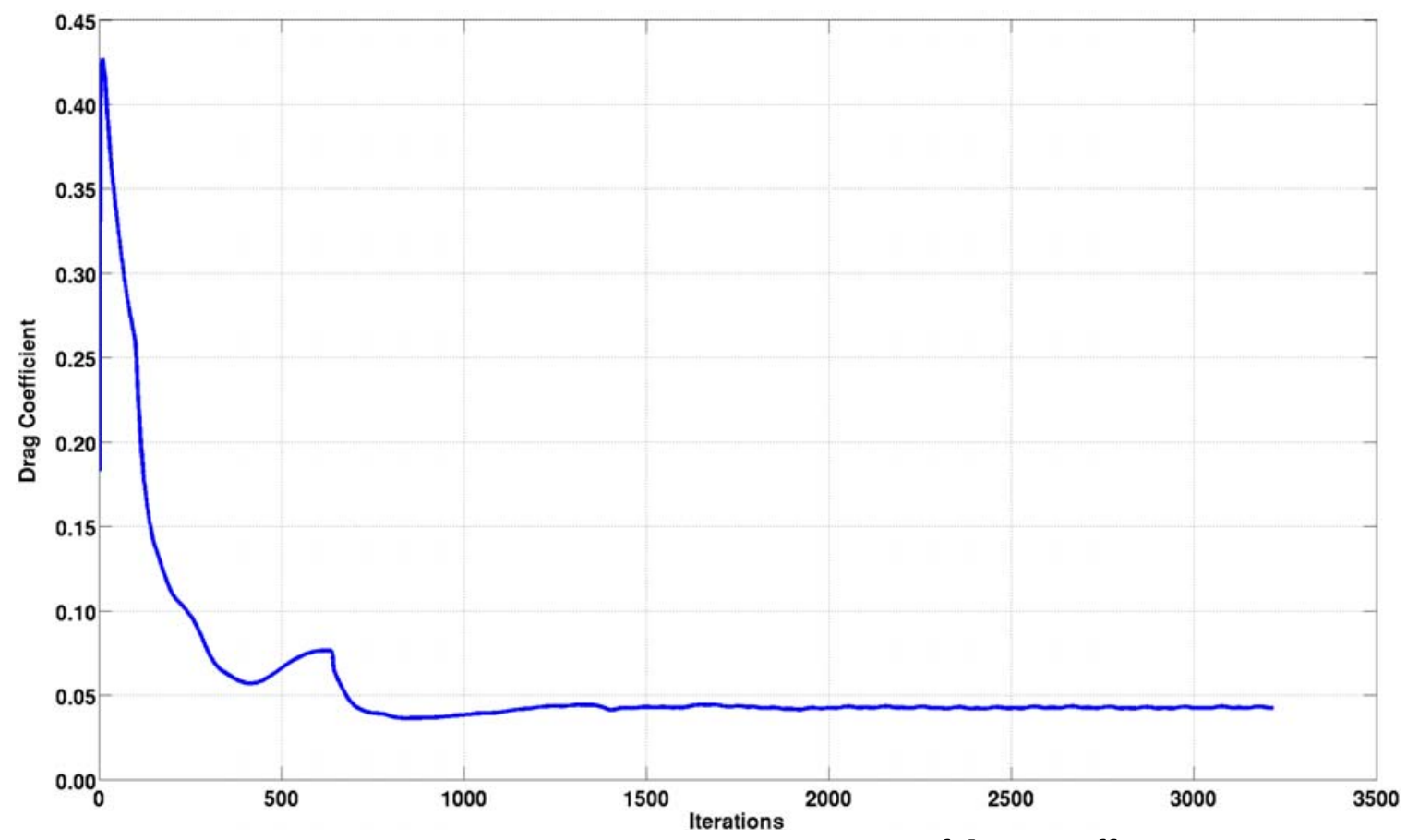

Figure 23: Iterative convergence monitoring of drag coefficient

\section{b). Grid Convergence}

The objective of grid convergence is to be able to distinguish the discretization error from any other source of error in the problem. If the discretized equations are defined to be strongly consistent, then the truncation error associated with the discretization asymptotically decreases with grid spacing and the discretization equations will converge to the exact PDEs. Reference [5] states that the discretization error associated with the solution is directly proportional to the truncation error. Thus, the discretization error should asymptotically approach zero as the grid spacing approaches zero. To achieve this result, a grid refinement study must be conducted. The grids must fall within the asymptotic region, but this can only be demonstrated by computing three solutions to three separate grids, each with a different grid resolution for a specified refinement ratio. Doing so will expose the discretization errors associated with computational solution. However, this type of convergence typically demands a large amount of computer resources, especially with complex problems such as the HWB and BWB configurations. It is often much simpler to achieve grid convergence on simpler models and determine if that is acceptable for the true model. To follow this suggestion, the authors have "turned off" the engines in hopes of creating grids that can be solved on available resources. The engine geometry itself still remains, however, the nacelle is now a flow through nacelle so air just passes through the engine without any energy being added. Once solutions of all three grids have been computed and demonstrates asymptotic behavior, Richardson's extrapolation can be used to estimate the order of the discretization error as well as the converged computational solution as the grid spacing approaches zero.

The three grids generated for this study consists of approximately 8, 16, and 24 million cells. Ideally, the mesh of 24 million cells should be around 32 million cells to ensure a constant refinement ratio of 2 . However, this was deemed too time consuming on available resources, thus forcing a trade off. Figure 24 is the result of the grid convergence study conducted for lift coefficient. 


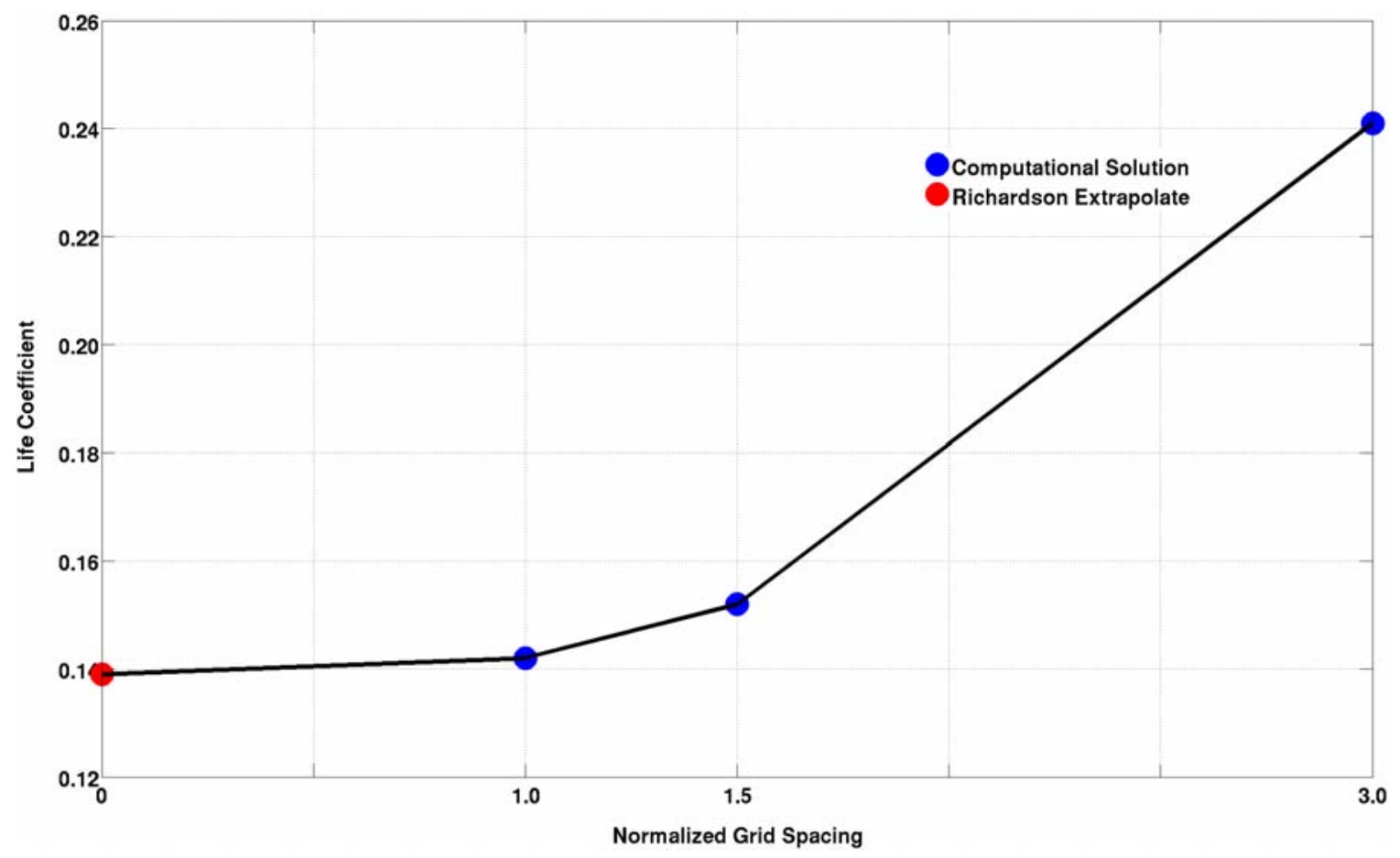

Figure 24: Grid Convergence

The final numbers of this study are shown in Table 7. The grid convergence index (GCI) was suggested by Roache [6] as a convenient way to not only track the convergence, but also provide an error bound as a plus or minus from the correct value.

Table 7: Grid independence data.

\begin{tabular}{|c|c|c|c|}
\hline & Mesh Size & $\mathrm{C}_{\mathrm{L}}$ & Grid Convergence Index \\
\hline Coarse & $\sim 8$ million & 0.241 & NA \\
\hline Medium & $\sim 16$ million & 0.152 & 9.38 \\
\hline Fine & $\sim 24$ million & 0.142 & 1.12 \\
\hline Predicted & Infinite & 0.139 & Base \\
\hline
\end{tabular}

There was no Richardson's extrapolation done on the drag coefficient because the drag is dominated by viscous effects so the mesh size is not directly related to the drag coefficient. A better study would be a $\mathrm{y}^{+}$study on the effect of using wall functions versus not using wall functions. This study will be preformed in Phase II. An error of $+/-1.12 \%$ seems to be acceptable. This suggests that the fine mesh be employed for all future numerical simulations to ensure that the discretization error is negligible.

\section{A. Validation Assessment}

Just like verification, validation becomes a important factor in the credibility of the CFD solutions obtained. However, validation assessment can only be conducted if there are test cases to compare the computational solutions to. This is the objective of Phase II: to design, construct, and test a scale model of the HWB in a wind tunnel. In the mean time, the authors are left with only being able to attempt verification assessment. 


\section{Future Work}

The HWB airliner concept from Phase I will be further refined in Phase II to become a more complete aircraft configuration. There are various projects underway for Phase II that will accomplish this goal. For example, a wide range of supercritical airfoils will be designed, analyzed, and optimized for peek performance during cruise conditions. At takeoff conditions, the airliner configuration will be evaluated at a flap deflections of $0,30,60$, and 90 degrees for a wide range of angle of attack. There are also interests in optimizing the location of the engine and the sizes of the CCW slots used on the leading and trailing edges of the wing. Also in the works is a code that will be able to fully automate the meshing and simulation process when given a set of inputs. A long with all of this, the meshing and numerical simulation process will be further investigated to understand how to generate CFD more effectively. The final objective will be to generate a full design space of this proposed future airliner concept.

\section{Conclusion}

Through the countless hours spent on Phase I, it was learned that the grid generation process not only was the most time consuming, but also the most important in considering an accurate computational solution. A well constructed mesh wields great influence on the numerical simulation. The instability or lack of convergence exhibited in all numerical simulations throughout the project almost always pointed to the quality of the grid as the main source of error. When higher quality meshes were generated, the likelihood of attaining the eventual solution increased significantly. Acquiring high quality grids certainly presents as much attention as it does prescribing the necessary physics to the problem at hand.

The conclusions that were able to be drawn from the takeoff and cruise solutions were that the HWB provided better lift to drag at zero angle of attack. At takeoff, the HWB provided a lift over drag nearly three times that of the BWB at the same angle of attack. Many intermediate solution checks were performed throughout the project to provide small checks that our solutions provided data that was not only real, but expected. Even though only a portion of the flight envelope was investigated, the authors are confident that the results obtained clearly demonstrate the HWB as the far superior airliner configuration. For these reasons it was the aerodynamics group's recommendation to go with the HWB because of its better aerodynamic performance. Fortunately, many of the other disciplines involved in this project shared a similar liking to the HWB.

The assessment of the computational solutions obtained thus far were by no means complete. It still lacks a validation assessment as well as key components of verification assessment. However, it was the authors goal to at least present to the reader that necessary steps are being employed in this project to ensure the credibility of all computational solutions obtained in the future. As a final remark to this paper, the authors hope to have shown that CFD can be effectively used to design full scale aircraft models with the only requirement that computational resources are sufficient, not to mention an understanding of CFD itself. As technology improves and become more affordable, this certainly becomes ever more possible for future CFD users.

\section{Acknowledgments}

This work was funded as part of a NASA Research Announcement award under Contract \#NNL07AA55C with Craig Hange and Joe Posey as the technical monitors. The authors wish to thank the excellent work of David Hall from DHC Engineering, Inc. in developing the designs of the aircraft that were the basis of this work. None of this would be possible if it were not for the excellent vision and leadership provided by Dr. David Marshall, always giving us the opportunity and necessary resources to learn. The solid models that were created from David Hall's designs were created by the brilliant work of Rory Golden. Jay Mark Marcos and Fletcher Hartshorn have proven to be invaluable resources throughout the entire contract helping wherever they are needed. This entire project is only possible because of the countless hours put in by all those involved and this paper provides only a small portion of the work accomplished so far. 


\section{References}

${ }^{1}$ Ansys ICEM CFD 11 SP1 Help Guide, 2007.

${ }^{2}$ DATCOM, The USAF Stability and Control Digital Datcom, AFFDL-TR-79-3032.

${ }^{3}$ Fluent 6.3 Users Guide, September 2006.

${ }^{4}$ Marshall, D. "The Integrated Modeling and Verification of Hybrid Wing-Body Low Noise ESTOL Aircraft,” Cal Poly SLO, NASA Contract NNL07AA55C, San Luis Obispo, CA, Nov. 2008, pp. 127-138.

${ }^{5}$ Oberkampf, W., Trucano, T., "Verification and Validation in Computational Fluid Dynamics," Sandia National

Laboratories, Contract DE-AC04-94AL85000, Albuquerqe, NM, Mar. 2002.

${ }^{6}$ Roache, P.J., K. Ghia, and F. White, "Editorial Policy Statement on the Control of Numerical Accuracy," ASME Journal of Fluids Engineering, Vol. 108,No. 1., March 1986, p. 2.

${ }^{7}$ Tu, J., Heng YEOH, G., and LIU, C, Computational Fluid Dynamics: A Practical Approach, Butterworth-Heinemann, Chicago, 2007. 